\title{
Muconic acid isomers as platform chemicals and monomers in the biobased economy
}

Received 00th January 20xx, Accepted 00th January 20xx DOI: $10.1039 / x 0 x \times 00000 x$

\begin{abstract}
Ibrahim Khalil a , Greg Quintens ${ }^{\text {b }}$, Tanja Junkers ${ }^{\text {b,c }}$ and Michiel Dusselier*a
Muconic acid (MA) is a high value-added dicarboxylic acid with conjugated double bonds, presenting three isomeric forms, i.e., cis,cis-MA, cis,trans-MA and trans,trans-MA. Its production is garnering increased interest owing to its potential as a starting material for the synthesis of value-added products as well as by being a versatile monomer for the production of specialty polymers. This review presents a systematic overview of production and synthesis routes to MA isomers as well as the routes for its final valorization. The production of MA through chemical pathways and the progress developed in the biotechnological pathways will be discussed. Traditional and new processes for achieving successful isomerization into the value-added trans,trans form of MA are also discussed and compared, with their constraints and possible solutions. The valorization of the three different isomers of MA into value-added chemicals such as adipic or terephthalic acids and MA polymers are summarized. Finally, the review concludes with a thorough summary, a practical insights section and an outlook. This work thus offers new perspectives and guidelines to tackle the challenges in MA chemistry, especially when aiming to combine an efficient biotechnological production of MA with its valorization .
\end{abstract}

\section{Introduction}

Muconic acid (MA), also referred to as 2,4-hexadienedioic acid, is a high value-added product with conjugated double bonds and reactive dicarboxylic groups. ${ }^{1}$ It is mainly used as a central precursor to monomers in the production of polyamides and polyesters. ${ }^{2}$ With a global market size of 79 million USD in 2018, the production of muconic acid is expected to rise to more than 110 million USD in 2024, according a compound annual growth rate of $7 \% .^{3,4}$ The significant interest directed to the production of muconic acid is due to its potential (1) as a starting material for the synthesis of value-added derivates such as adipic acid, caprolactam, terephthalic acid (TPA) and others; or (2) as a bulk chemical used in polymer reactions to produce muconic homoand copolymers. ${ }^{2,5-8}$ Current commercial usages of muconic acid derivatives per application type are illustrated in Fig. 1, with carpets and textiles, plastics and lubricants. ${ }^{9}$ The textile industry, known to be the most important end user of MA, is expected to show a growth of about 3 to $5 \%$ over the next five years. Additionally, rising demands for lubricants and packaged products (containers, bags, films...) explain the expected growth in the global MA market in the coming years. MA can also occur in humans, as it is a metabolite of benzene in vivo (thus used as a biomarker in urine)..$^{10,11}$ The very functionalized nature of MA and its 6-carbon skeleton renders it similar to

\footnotetext{
a. Center for Sustainable Catalysis and Engineering (CSCE), KU Leuven,

Celestijnenlaan 200F, B-3001 Leuven, Belgium.

b. Institute for Materials Research (IMO), Hasselt University, Martelarenlaan 42, 3500 Hasselt, Belgium

c. Polymer Reaction Design group, School of Chemistry, 19 Rainforest Walk, Monash University VIC, 3800, Australia

*Corresponding author: michiel.dusselier@kuleuven.be
}

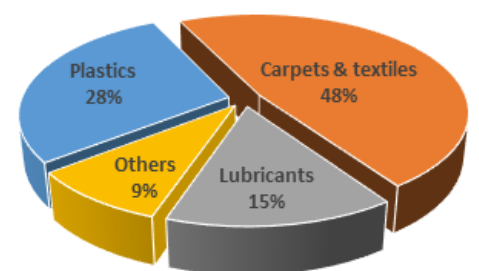

Fig. 1 - Overview by volume percentage of the global market of MA by application in 2014.

highly functionalized sugar (hexoses) and lignin biomass feedstocks. The C/O ratio of MA is 1.5 (vs. 1 for glucose), and on top of $\mathrm{O}$, it contains two reactive double bonds. From a functional group analysis, as well as an atom economy point of view, biobased routes for MA seem reasonable. ${ }^{12}$

MA presents three isomeric forms designated cis,cis-muconic acid (ccMA), cis, trans-muconic acid (ctMA) and trans, transmuconic acid (ttMA). The three isomers differ by their chemical and physical properties as well as by their applications. $2,5,13-15$ Table 1 gathers the different properties of these three isomers of muconic acid. Both ccMA and ctMA present almost similar properties in term of melting point and pKa values, whereas ttMA, due to its high packing ability, has a higher melting point. Moreover, this isomer shows a higher first pKa value (for the first of two acid group reactions) as given by Tessonnier et al. ${ }^{5}$ In term of solubility, ctMA isomer can have greater solubility than the ccMA isomer in aqueous media, while ttMA shows a very low solubility in these conditions. The solubility of these 
<smiles>CCOC(=O)C(Br)C(Br)CCC(=O)O</smiles>

(b)<smiles>COC(=O)CC(Br)C(Br)CC(=O)OC</smiles>

(e)<smiles>O=C(O)[C@@H](O)[C@@H](O)[C@H](O)[C@@H](O)C(=O)O</smiles>

(d)<smiles>COC(=O)/C=C/C=C/C(=O)OC</smiles><smiles>[3H][13CH3]</smiles><smiles>[3H][Hg]</smiles><smiles>[CH][TlH]</smiles><smiles>C=C/C=C\C(=O)OC</smiles><smiles>CC(C)COC(=O)C=CC=CCCCCC(=O)O</smiles>

(a)<smiles>COC(=O)CC1=CC(=O)OC1</smiles>

(l) (h)

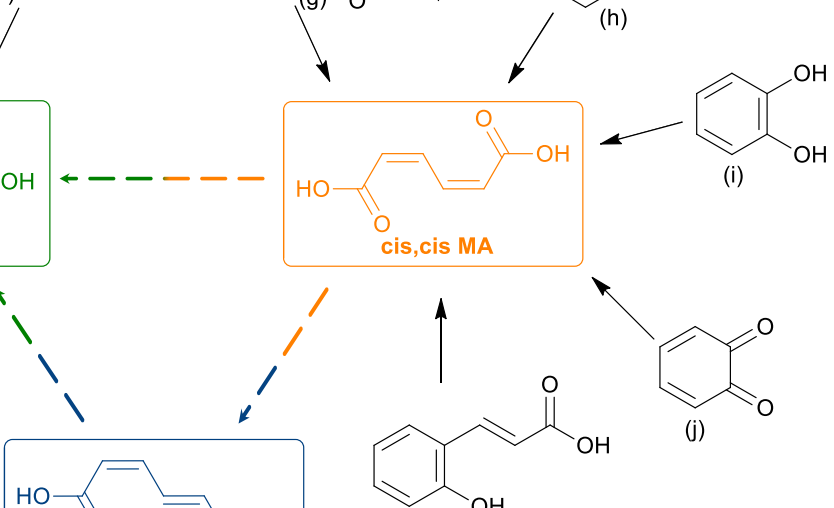

(i)

(k)

Fig. 2 - Summary of the possible chemical routes to synthesise the three isomers of MA.

isomers was estimated in the course of writing this review, in several solvents (DMSO, ethanol, THF and Toluene, see Table 1). The solubility of all MA isomers increased in organic solvents, however the order of the solubility was intact, where ttMA remains the one with the lowest solubility. Despite its low solubility, the ttMA isomer has the potential utility of being used

Table 1 - Melting points $\left({ }^{\circ} \mathrm{C}\right)$, pKa (relative to acetic acid) and solubility values in $\mathrm{H}_{2} \mathrm{O}$ at $15^{\circ} \mathrm{C}$ and other solvents for the three isomers of MA and tt-muconic ester.

\begin{tabular}{cccccccc}
\hline & $\mathrm{MP}$ & & \multicolumn{5}{c}{ Solubility (g/L) } \\
& $\left({ }^{\circ} \mathrm{C}\right)^{15}$ & $\mathrm{pKa}^{5}$ & $\mathrm{H}_{2} \mathrm{O}^{5}$ & $\mathrm{DMSO}^{*}$ & $\mathrm{EtOH}^{*}$ & $\mathrm{THF}^{*}$ & Toluene* \\
\hline cCMA & 195 & 2.9 & $\approx 1.0$ & $\approx 400$ & $\approx 28$ & $\approx 50$ & $<0.05$ \\
ctMA & 191 & 2.9 & 5.2 & $>500$ & $\approx 90$ & $\approx 125$ & $<0.10$ \\
ttMA & 300 & 3.4 & $<0.1$ & $\approx 35$ & $\approx 2.5$ & $\approx 3.0$ & $<0.02$ \\
ttDEM* & $\approx 50$ & $/$ & $\mathrm{NM}$ & $\mathrm{ND}$ & $\approx 50$ & $>500$ & $>500$ \\
\hline
\end{tabular}

NM: not miscible, ND: not determined. ${ }^{*}$ Values measured in this work at $20^{\circ} \mathrm{C}$ for a rough estimate (large errors possible). Conditions: In $2 \mathrm{ml}$ glass vials, $1 \mathrm{ml}$ of each solvent was mixed with a selected amount of the specific isomer. After continuous stirring at $25^{\circ} \mathrm{C}$ for 1 hour, the solution was filtrated. $100 \mu$ of the solution was then taken out and the dissolved amount was calculated by weighing after solvent evaporation. For lower solubility values, larger solutions were prepared (10-20 $\mathrm{ml}$ ). The conformation of MA isomers was checked, by $1 \mathrm{H}-\mathrm{NMR}$ after the solubility measurements, to validate the absence of any isomerization (especially from ccMA to ctMA) under these conditions. as a reactant in Diels-Alder reactions, as a trans,trans and thus accessible diene. ${ }^{16}$

Traditional ways of producing muconic acid rely on the chemical transformation of non-renewable petroleum-based feedstocks (catechol, phenol...) in presence of acids or heavy metal catalysts (Fig. 2).1,14,17,18 Recently, biomass based renewable resources are gaining both social and commercial interest and the door to the synthesis of MA through biological routes has been firmly opened. The production of MA through chemical routes can give the three isomeric forms, whereas in biological routes, mainly ccMA and ctMA are obtained. ${ }^{13,16}$ The ttMA can be further obtained by isomerization reactions using hydrogenation catalyst such as palladium supported over carbon $(\mathrm{Pd} / \mathrm{C}),{ }^{16}$ or using iodine $\left(\mathrm{I}_{2}\right)$ under reflux reactions or under UV irradiation. ${ }^{2,13}$

In a first part of this work, we will provide a systematic review of the synthesis of MA through chemical routes and briefly comment on the best results obtained through biotechnological routes. In a second part, isomerization processes proposed to obtain the value-added ttMA will be detailed. In a third part, the valorization of the different muconic acid isomers into important platform chemicals such as adipic acid, lactones and terephthalic acid will be presented. Finally, we will discuss the 
options to directly involve muconic acid and its derivates in polymerization reactions. A holistic approach to this potential platform molecule is thus presented. A critical summary and outlook are given at the end, on top of a practical insights section.

\section{Synthesis routes}

Several attempts to produce and identify the three isomers of MA have been published. In this section, attempts to produce MA by both chemical transformation and biological fermentation are reviewed. The latter are treated brief and highlight the maximum obtained reported rates, since some overviews on these biotech routes exist. ${ }^{19,20}$ The current commercial production of MA is guided by key vendors, e.g. Amyris, Merck, Myriant (GC Innovation America), Santa Cruz Biotechnology, and others, where the synthesis seems mostly performed by the biotechnological transformation of sugar feedstocks (e.g. glucose and sucrose) and certain aromatic compounds, such as catechol. ${ }^{3}$ However, there is little rigorous information on the production methods actually used.

\section{Chemical routes}

The chemical reactions, reported in the literature, for the synthesis of the different isomers of MA are summarized in Fig. 2. As shown, muconic isomers can be obtained as products of the same reaction as shown in the case of the compound " $e$ " that produces ccMA and ctMA, or from different reactants as shown for the other compounds. The dotted lines in the Fig. 2 represent the isomerization reactions allowing to obtain ttMA directly from ccMA or after a prior isomerization to ctMA, these reactions will be discussed in a later section.

\section{The trans,trans isomer}

The trans,trans isomeric form of MA was the first to be synthesized. Its synthesis was reported at the end of the $19^{\text {th }}$ century, by Rupe et al. ${ }^{21}$ The obtained product presented a melting point of almost $300^{\circ} \mathrm{C}$ and was assigned 26 years later by Behrend to the ttMA. ${ }^{22}$ The reaction consisted of adding alcoholic potassium hydroxide to 3,4-dibromohexanedioic acid (Fig. 2 - compound a) dissolved in ethanol. After few minutes of reflux, the obtained K-salt precipitate was washed several times with ethanol before being dissolved in water. The ttMA was then precipitated from water by acidification with sulfuric acid, filtered and recrystallized to give very small white needles with an isolated yield of $85 \%$. In the same period, Ruhemann and Blackman also succeed in the production of the ttMA by warming diethyl 2,3-dibromoadipate (Fig. 2 - compound b) in the presence of alcoholic potassium hydroxide. ${ }^{23}$ After $\mathrm{HBr}$ elimination, dilution in water and acidification in hydrochloric acid, white needles were obtained with a boiling point of almost $320^{\circ} \mathrm{C}$. The authors initially named it as "isomuconic acid", but later, the nomenclature of Rupe et al. was adopted. ${ }^{24}$ The alcoholic potassium hydroxide was also used by Ingold to transform the 2,5-dibromohexanedioic acid (Fig. 2 - compound c) and its ester into the ttMA isomer. ${ }^{25}$ The authors noted the effect of the conformation of the carbon atoms holding the $\mathrm{Br}$ in the used diester, e.g. for meso dibromo ester the reported yield was $55 \%$ whereas using the racemic dibromo ester ( $R R+$ SS) the muconic acid was produced with a total yield of $60 \%$. In the same work, the conversion of diiodo esters into MA was also shown with a yield of $33 \%$ in case of the meso ester substrate and $78 \%$ for the racemic ester. In recent years, Shiramizu et al. reported the synthesis of ttMA from mucic acid (Fig. 2 compound d), a sugar-based feedstock that derived from the oxidation of galactose, by an innovative double deoxydehydration reaction (DODH), using 3-pentanol as a sacrificial reductant. ${ }^{26}$ The one pot reaction was catalyzed by 5 mol\% of soluble methyltrioxorhenium $\left(\mathrm{CH}_{3} \mathrm{Re}^{\mathrm{VII}} \mathrm{O}_{3}\right)$. After 15 hours under air at $155^{\circ} \mathrm{C}, 43 \%$ of stereo stable ttMA was obtained, accompanied by dipentan-3-yl muconic ester (14\%). ${ }^{26}$ The mechanism, proposed by Shiramizu et al., and adapted by Qu et al., for the formation of ttMA from mucic acid by DODH catalyzed reaction is shown is Fig. 3.26,27 Similar mechanism can be adopted when working with esters. As the muconic ester was easier to manipulate and purify than ttMA, e.g. high solubility of muconic ester in organic solvents (Table 1), the authors sought to shift the selectivity towards the ester product. Thus, $\mathrm{CH}_{3} \mathrm{ReO}_{3}$ was replaced with perrhenic acid $\left(\mathrm{HReO}_{4}\right)$ that was identified in earlier studies as a promising DODH catalyst. $26,28,29$ Moreover, the Brønsted acidity of this catalyst may in situ catalyze the esterification of mucic acid. After adding $7 \mathrm{~mol} \%$ of $\mathrm{HReO}_{4}$ in $6 \mathrm{~mL}$-butanol (more sterically accessible alcohol than 3 -pentanol) containing mucic acid $(0.3 \mathrm{mmol})$ at $170^{\circ} \mathrm{C}$, a $62 \%$ yield of trans,trans-dibutyl muconate was obtained after 15 hours (air). When working under inert atmosphere (N2), 71\% of dibutyl muconate were obtained in 7.5 hours at the same temperature. After a pre-esterification step of mucic acid (reflux in n-butanol with $\mathrm{HCl}$ ), dibutyl mucic ester was almost quantitatively converted (94\%), by the activity of $5 \mathrm{~mol} \%$ of $\mathrm{HReO}_{4}$, into trans, trans dibutyl muconate after 6 hours under

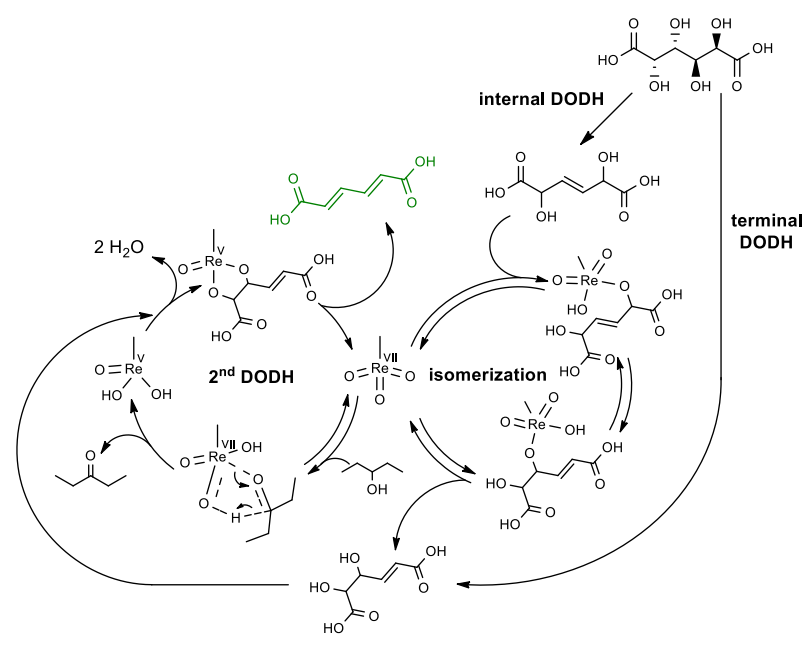

Fig. 3 - Proposed catalytic cycle for the transformation of mucic acid into ttMA by $\mathrm{CH}_{3} \mathrm{ReO}_{3}$ (VII) catalyzed DODH reaction. Reproduced from ref. 26 with permission from Wiley, copyright 2013, and adapted based on ref. 27. 


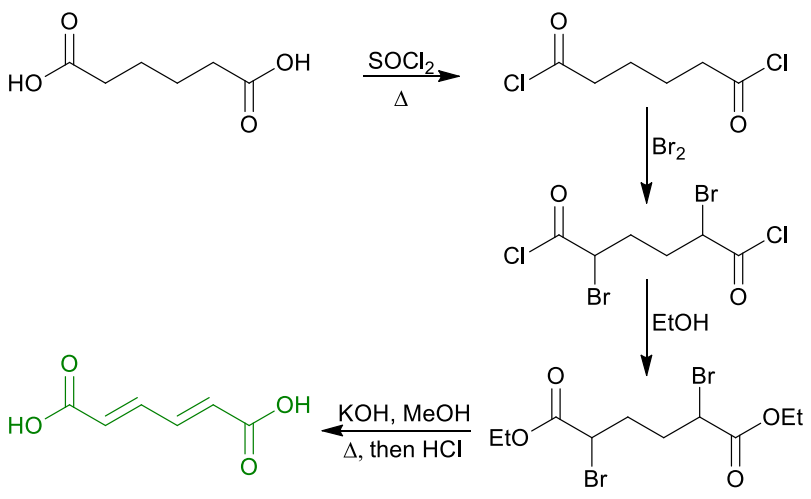

Fig. 4 - Chemical route for the production of trans,trans MA from adipic acid.

$\mathrm{N}_{2} \cdot{ }^{26,28}$ By adjusting the conditions of the one pot esterification/DODH reactions, $\mathrm{Li}$ et al. have achieved a quantitative transformation of mucic acid into trans,transdibutyl muconate after 12 hours. ${ }^{29}$ The reaction consists on adding 5 mol\% of $\mathrm{Re}_{2} \mathrm{O}_{7}$ (which reacts easily with moisture to form $\left.\mathrm{HReO}_{4}\right)$ in a solution of $\mathrm{n}$-butanol $(20 \mathrm{~mL})$ and mucic acid (1 mmol) under $\mathrm{N}_{2} .^{29}$

ttMA was also produced from the chemical transformation of adipic acid as shown in Fig. 4. In a first step, adipic acid was refluxed in thionyl chloride $\left(\mathrm{SOCl}_{2}\right)$ for 3 hours to quantitively form the acid chloride. After extraction of the excess of $\mathrm{SOCl}_{2}$ dry bromine was added, and the solution was heated for 2 hours, then large excess of ethanol was added and diethyl 2,5dibromoadipate was produced and purified with a yield of 91$97 \%$. In a second step, debromination and hydrolysis reactions of diethyl 2,5-dibromoadipate were performed at $100^{\circ} \mathrm{C}$ in a solution of methanol and potassium hydroxide. After filtration, purification (charcoal) and crystallization (water $+\mathrm{HCl}$ ) steps ttMA was produced with a yield of $37-43 \% .^{30}$ Nowadays, this method is no longer satisfying from an economic point of view due to the high demand of adipic acid as a monomer in the polymerization reaction to produce nylon- $6,6 .{ }^{14}$ Conversely, the hydrogenation of MA is currently one of the eyed routes for the production of adipic acid, as detailed in 'Transformation of MA into valuable chemicals' below.

\section{The cis,cis isomer}

Aiming to obtain other isomeric forms of muconic acid, e.g. cis,cis and/or cis,trans isomers, in 1923, Farmer studied the debromination reaction of dimethyl 3,4-dibromohexanedioate (Fig. 2 - compound e) using pyridine. ${ }^{31}$ Two isomers of the dimethyl muconic ester (DMM) with different boiling points $\left(156^{\circ} \mathrm{C}\right.$ and $\left.75^{\circ} \mathrm{C}\right)$ were identified and attributed respectively to ttDMM (Fig. 2 - compound f) and ccDMM (Fig. 2 - compound g). A small amount of an oily ester was also obtained and thought to represent the third isomer (cis,trans). Owing to experimental difficulties, this could not be verified. ${ }^{31}$ ttMA was obtained after adding sulfuric acid to the ttDMM, whereas ccMA was obtained, for the first time, by adding sodium methoxide to the ccDMM. During the following ten years, Böeseken et al. ${ }^{32-35}$ reported several attempts to produce the ccMA isomer. Their work focused on examining the oxidation behavior of the peracetic acid $\left(\mathrm{CH}_{3} \mathrm{CO}_{3} \mathrm{H}\right)$ for the ring opening reactions of branched benzene molecules, e.g. phenol (Fig. 2 - compound h), 32,33 catechol (Fig. 2 - compound i) ${ }^{34}$ and ortho-quinone (Fig. 2 compound j). ${ }^{35}$ The authors found that while benzene was not attacked by peracetic acid, introducing one or more hydroxyl groups made the aromatic ring more sensitive towards the acid. The maximum yield of ccMA (35 mol\%) was obtained after 10 days of oxidizing phenol with $10 \%$ of peracetic acid. ${ }^{33}$ In addition, Grundmann has shown that the oxidation of $2.8 \mathrm{~g}$ of o-coumaric acid (Fig. 2 - compound k) with peracetic acid provided, after 14 days in the dark, $112 \mathrm{mg}$ of ccMA (molar yield $\approx 4 \%) .{ }^{36}$ Nowadays, the cleavage of catechol to produce ccMA can be performed via biotechnological pathways using adapted strains, e.g. C. glutamicum, as we will discuss in the following section. So far, the ctMA isomer was still unknown for all the previous authors.

The monoester of cis,cis-muconic acid can be also produced by chemical pathways. The reactions consists of the oxidative cleavage of catechol and phenol. ${ }^{18}$ The oxidation reaction with $\mathrm{CuCl}$ in pyridine was investigated in presence of oxygen and alcohol (methanol, ethanol, n-propanol, i-propanol or $\mathrm{n}$ butanol). In absence of oxygen the reaction can be carried out with $\mathrm{KO}_{2} / \mathrm{CuCl}_{2}$ and $\mathrm{KOH} / \mathrm{CuCl}_{2}$ catalysts in pyridine containing alcohol. The alcohol used had a critical effect on the yield of produced monoester of cis,cis-muconic acid. The yields decrease with an increasing length of its alkyl chain, e.g. attaining $82 \%$ when using methanol and $7 \%$ for isopropanol while no muconoester was formed for $n$-butanol. ${ }^{18}$

\section{The cis,trans isomer}

As shown in Table 1, the cis,cis and the cis,trans isomers of muconic acid show remarkable similarity, which has concealed the existence of the cis,trans isomer for 27 years after the identification of the cis,cis isomer. After a significant amount of work on MA synthesis, Elvidge et al. ${ }^{15}$ succeeded to provide the first definitive identification of the cis,trans muconic isomer. The preparation consists in isomerizing the methyl (2-oxo-2,5dihydrofuran-3-yl)acetate (Fig. 2 - compound I) with sodium methoxide in methanol into the trans,cis monomethyl muconic ester (Fig. 2 - compound $\mathrm{m}$ ) yielding ctMA after alkaline hydrolysis. A study of the stability of ccMA and ctMA, by the same authors, show that ccMA can be quantitatively converted into ctMA isomer only by boiling water. The effect of this observation on the results obtained by earlier workers in the field of ccMA synthesis remain uncertain.

\section{Biotechnological routes}

The chemical routes, detailed above, rely mostly on nonrenewable petroleum-based products or derivatives. Mucic acid, for the DODH, can be potentially derived from sugars. Due to geopolitical issues, the finite nature of petroleum and climate concerns over fossil $\mathrm{CO}_{2}$ emissions, routes for supplying energy (and energy carriers) and especially chemicals from renewable resources such as biomass come to the fore. ${ }^{37-40}$ With potential 
Table 2 - Summary of the best muconate titers obtained in bacterial fed-batch pathways from different substrates.

\begin{tabular}{|c|c|c|c|c|c|c|}
\hline Substrate & Microorganism & $\mathrm{pH}$ & Products* & Titer $(\mathrm{g} / \mathrm{L})$ & Yield & Reference \\
\hline Catechol & C. glutamicum & 7 & $\operatorname{ccMA}^{2-}$ & 85.0 & $100 \%$ & Becker et al. ${ }^{48}$ \\
\hline Glucose & E. coli WN1/pWN2.248 & $\sim 6.5$ & $\mathrm{ccMA}^{2-}$ & 59.2 & $30 \%$ & Frost et al. ${ }^{13}$ \\
\hline Toluene & Pseudomonas sp. DCB-71 & 6.9 & $\mathrm{ccMA}^{2-}$ & 45.0 & $96 \%$ & Chua et al. ${ }^{57}$ \\
\hline Benzoate & Arthrobacter sp. T8626 & $7-8.5$ & $\mathrm{ccMA}^{2-}$ & 44.1 & $96 \%$ & Mizuno et al. ${ }^{4 \varsigma}$ \\
\hline
\end{tabular}

applications of MA in the manufacture of (bio-)plastics, agrochemicals and others, research into the biotechnological production of MA is expected to intensify in coming years. ${ }^{1,2}$ Biotechnological routes producing MA by the ortho-cleavage of catechol were developed.1,41-45 Catechol is obtained by the oxidation of petroleum-based aromatic compounds (benzoate, toluene, benzene, phenol...) by adapted bacteria. ${ }^{46}$ Then, using catechol 1,2-dioxygenase, the ortho-cleavage of catechol can be performed to yield MA. ${ }^{46}$ In the last years, the development in the biomass conversion schemes opens routes to obtain catechol, phenol and other aromatic compounds directly from biomass feedstocks, creating new petroleum-free methods for producing MA. ${ }^{47-51}$

The highest titers were reported from the fed-batch transformation of catechol using biological strains (Table 2). Fed-batch processes were used to control the substrates concentration below the inhibitory levels, and thus increase the productivity by avoiding substrate toxicity on the bacteria during production. Becker et al. have studied the activity of a modified Corynebacterium glutamicum (C. glutamicum) strain on the production of MA from catechol. ${ }^{48}$ The production was conducted in a shake flask, in which the metabolically engineered strain was continuously fed with catechol and glucose to maintain a level of glucose in the region between 5 $15 \mathrm{~g} / \mathrm{L}$. The $\mathrm{pH}$ of the solution was kept constant at almost 7.0 by manual addition of $2 \mathrm{M} \mathrm{NaOH}$. After 60 hours, $85 \mathrm{~g} / \mathrm{L}$ cis,cis muconate $\left(\mathrm{ccMA}^{2-} ; 2 \mathrm{Na}^{+}\right.$) had accumulated (Table 2$) .{ }^{48}$ So far, this represents the highest reported titer of MA. Compared with the chemical production of ccMA from catechol, biotechnological processes show the advantages of high productivity and selectivity, with a final yield of $100 \%$ in comparison to less than $35 \%$ and low purity obtained with the chemical cleavage of catechol. ${ }^{33,34}$ Kohlstedt et al. also reported the biotechnological production of ccMA ${ }^{2-}$ from catechol using an engineered $P$. putida strain. ${ }^{52}$ Within 55 hours the authors reported the production of $64.2 \mathrm{~g} / \mathrm{L}$ of cis,cis muconate. ${ }^{52}$ Kaneko et al. used $E$. coli $p E / c a t A$ strain to produce, after successive addition of catechol for 12 hours, $59.0 \mathrm{~g} / \mathrm{L}$ of muconic acid (Table 2). ${ }^{43}$ Another common aromatic substrate is sodium benzoate, that presents the advantages of low prices, water solubility as well as being non-volatile. Different types of microorganisms were reported to metabolize benzoate into MA, such as Sphingobacterium, Corynebacterium, Brevibacterium, Arthrobacter, P. putida, Pseudomonas and others. ${ }^{49,53-56}$ Indeed, the best titer was obtained using an
Arthrobacter sp. mutant strain in a fed-batch process by successively adding an aqueous solution containing $35.1 \mathrm{~g}$ of sodium benzoate into the $15 \mathrm{~L}$ culture at 2 hours intervals. After 48 hours ( 24 additions), the volume of the medium increased to 16.3 litres and $44.1 \mathrm{~g} / \mathrm{L} \mathrm{ccMA}^{2-} ; 2 \mathrm{Na}^{+}$were produced, indicating a conversion of $96 \mathrm{~mol} \%$ (Table 2)..$^{49}$ Using toluene as substrate to produce MA was also reported in the art, ${ }^{41,57-60}$ the best titer being with a Pseudomonas $s p$. strain in fed-batch reactor. ${ }^{57}$ After 4 days of successively feeding small amounts of toluene at neutral $\mathrm{pH}, 45.0 \mathrm{~g} / \mathrm{L}$ of $\mathrm{ccMA}^{2-}$ were produced with a molar yield of 96 mol\% (Table 2)..$^{57}$ P. putida was also used in fed-batch reactors to produce MA from toluene, ${ }^{41,58-60}$ the highest obtained titer there being only $27 \mathrm{~g} / \mathrm{L}$ of mainly $\mathrm{ccMA}^{2-}$ and a small amount of ctMA ${ }^{2-} .{ }^{60}$ Because of its flammability and volatility in comparison to other aromatic substrates, toluene required more adapted control of the biotech process. ${ }^{61}$

So far, all the aforementioned biotechnological routes use petroleum-derived or lignin-derived aromatic compounds. To produce MA directly from glucose, an engineered Escherichia coli WN1/pWN2.248 was shown to be the most apt strain. After 48 hours of cultivation under fed-batch conditions, Niu et al. ${ }^{62}$ reported the production of $36.8 \mathrm{~g} / \mathrm{L}$ of cis, cis muconate with a $\mathrm{mol} / \mathrm{mol}$ yield of $22 \%$. Further optimizations of the fermentation process by Frost et al. have led to $59.2 \mathrm{~g} / \mathrm{L}$ of cis, cis muconate at a yield of $30 \%$ in 88 hours (Table 2). ${ }^{13}$ This result represents the highest reported titer of MA from glucose, in fed-batch conditions. 1,13,63 Other attempts were reported with modified E. coli strains (E. coli MA-4, E. coli AB2834 and E. coli $M Y R 428$ ), yielding titers in the range of 0.002 to $16.0 \mathrm{~g} / \mathrm{L} .{ }^{64-66} \mathrm{~S}$. cerevisiae, a yeast strain, has also been used for this fermentation, ${ }^{67-69}$ the highest obtained titer being $2.1 \mathrm{~g} / \mathrm{L}$ for a molar yield of $1.6 \%$, as reported by Leavitt et al. ${ }^{69}$ These values clearly show the limited performance so far of $S$. cerevisiae strain (yeast) towards biotechnological MA production from glucose, in comparison to E. coli strain (bacteria).

As Table 2 summarizes, the cis,cis isomer is the one mainly forming in biological pathways. Some cis,trans isomer was also identified, however, the more desirable trans, trans isomer was never observed in biotechnological process conditions. ${ }^{2}$ Matthiesen et al. reported that ttMA formation requires chemical activation. ${ }^{5}$ The isomerization reactions, detailed in the next section, can be performed in situ or ex situ after extraction and purification. Vardon et al. ${ }^{70}$ have reported a downstream purification process for MA from the fermentation broth (titer of $34.5 \mathrm{~g} / \mathrm{L}$ ). Membrane filtration, carbon adsorption 
for impurities removal, salt precipitation and ethanol washing of crystals were applied to achieve $99.8 \%$ purity with recovery yield of $81.4 \%$. Moreover, Frost et al. ${ }^{13}$ have described the use of a crystallisation process followed by methanol, ethanol or isopropanol wash to achieve a desired purity of muconic acids. A patent by Bui et al. ${ }^{71}$ reported that the isomerization of the cis,cis muconate and its recovery as cis, trans from fermentation broth can be achieved by applying extraction, precipitation, ionexchange chromatography, selective membrane separation, electrodialysis, or other methods known in the art. The patent describes the recovery of ctMA ${ }^{2-}$ by crystallization using one or more of the following organic solvents: methanol, ethanol, propanol, isopropanol, butanol, acetic acid, acetonitrile, acetone, and tetrahydrofuran. It is clear that biotechnological production routes not only need to focus on high titers (and preferably in a short time: thus, high productivity), but also on the subsequent and challenging isolation and purification of MA from the broth.

\section{Isomerization reactions}

In this part, isomerization routes for MA (colored triangle in Fig. 2) will be extensively reviewed, and these are especially of interest for the biologically produced ccMA, e.g. to turn it into the value-added and thermodynamically preferred ttMA isomer. Settle et al. have calculated the relative enthalpies of the six isomers of DMM. ${ }^{72} 6$ isomers were identified instead of 3 because of the possible conformation (cis or trans) of the C3C4 single bond, named $\sigma$, considered by the authors (Erreur! Source du renvoi introuvable.). Calculated values are relative to $\sigma$-cis, $\pi$-ccDMM ( $\sigma$ refers to the C3-C4 single bond, and $\pi$ refers to both $\mathrm{C} 2=\mathrm{C} 3$ and $\mathrm{C} 4=\mathrm{C} 5$ double bonds). For all isomers, the $\sigma$-trans configurations were more stable than $\sigma$-cis configurations. The latter can be identified as intermediates during isomerization and chemical transformation reactions (e.g. Diels-Alder cycloaddition) of MA and esters. With a relative computed enthalpy of $-38.5 \mathrm{~kJ} / \mathrm{mol}$, the $\sigma$-trans, $\pi$-ttDMM was identified as the lowest energy species, followed by $\sigma$-cis, $\pi$ ttDMM and $\sigma$-trans, $\pi$-ctDMM with -26.3 and $-28.0 \mathrm{~kJ} / \mathrm{mol}$, respectively. The interconversion of ccMA to the thermodynamically more stable ttMA is often a two-step reaction, where ctMA is the intermediate obtained in a first isomerization. In a second step, ctMA will be isomerized into ttMA. In literature these reactions were reported either in one pot systems using ccMA as starting material (ccMA to ttMA), or in two reactions separated by a purification step (ccMA to ctMA, purification and then ctMA to ttMA). Due to the higher stability of the $\sigma$ bonds in the trans conformation (for all the $\pi$-isomers) and the little attention to it in reported literature, the $\sigma$ conformation will be neglected in the following parts and we will only discuss the $\pi$-bonds isomers of MA.

\section{From the cis, cis to the cis,trans isomer}

The formation of ctMA from ccMA is known to be spontaneous as reported by different researchers. ${ }^{2,13,73}$ The energy barrier of

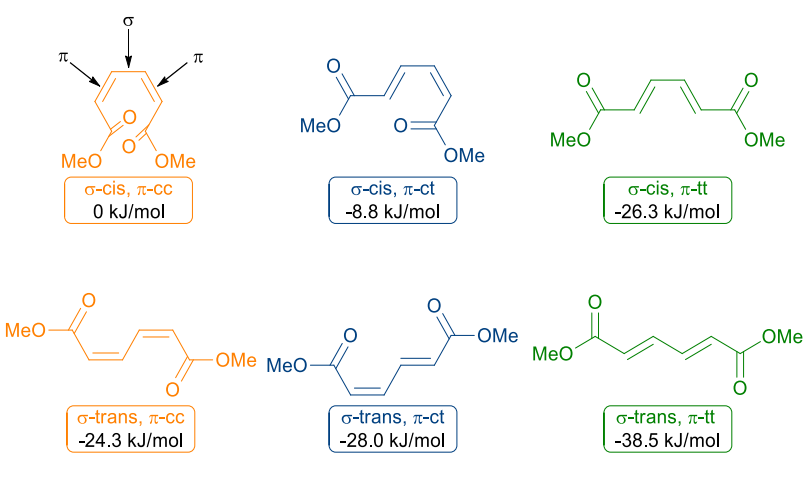

Fig. 5 - The six possible isomers of dimethyl muconates (DMM) and their computed enthalpies relative to $\sigma$-cis, $\pi$-cc DMM. $\sigma$ refers to the C3-C4 single bond, while $\pi$ refers to both $\mathrm{C} 2=\mathrm{C} 3$ and $\mathrm{C} 4=\mathrm{C} 5$ double bonds.

this transformation is medium-low $(76 \pm 1 \mathrm{~kJ} / \mathrm{mol})^{2}$, allowing the isomerization to occur even at room temperature. ${ }^{5,74}$ Frost et al. ${ }^{73}$ reported the transformation of $15 \mathrm{~g}$ of ccMA into the ctMA in refluxing water $(150 \mathrm{~mL})$. After 15 minutes, $69 \%$ of ctMA was produced (theoretically, this should be at $\mathrm{pH} \approx 1.5-2$ ). Muconolactone (Mlac) was also obtained as a side product (25\%, see structure in Fig. 11). Increasing the $\mathrm{pH}$ of the solution, prohibits lactone(s) formation and gives better selectivity towards the isomerization product (Table 3 ).

The group of Tessonier 75 has reported the full conversion of ccMA into ctMA in 20 minutes in water at $83^{\circ} \mathrm{C}$. They reported the same yield (Carraher et al. ${ }^{2}$ ) after 30 minutes in water at $75^{\circ} \mathrm{C}$ (Table 3). Carraher et al. also studied in detail the effect of $\mathrm{pH}$ on the isomerization mechanisms at $90^{\circ} \mathrm{C}$. When the $\mathrm{pH}$ values are lower than the $\mathrm{pKa}_{1}$ of $\mathrm{ccMA}\left(\mathrm{pKa}_{1}=2.9\right)$, the isomerization reaction is said to occur by a simple rotation of the $\mathrm{C}-\mathrm{C}$ single bond, as shown in Fig. 6 -a. For $\mathrm{pH}$ values ranging between the first and second pKa values $(2.9<\mathrm{pH}<4.0)$, cis, cis mono-muconates are present in the media ( $\left.\mathrm{ccMA}^{-}\right)$allowing an intramolecular attack between the cis-carboxyl group and its interior $\mathrm{C} 4$ adjacent carbon. The $\mathrm{C}-\mathrm{C}$ rotation takes place and the cis,trans isomer is obtained (Fig. 6-b). Above pH 4.0, mainly cis,cis muconates $\left(\mathrm{ccMA}^{2-}\right)$ are present in the solution which remain stable with the reaction time. Their stability may be the result of resonance structures, in which equal opposite intramolecular carboxylate-C4 interactions stabilize the isomer (Fig. 6-c). ${ }^{2}$ Regarding this part, we conclude that ccMA to ctMA isomerization can be achieved preferentially at $\mathrm{pH}$ values below 4 and that the reaction time depends on the temperature. The cc to ct isomerization can also occur at low temperature, e.g. studied by Matthiesen et al. for ccMA at $22.5^{\circ} \mathrm{C}$ in water at $\mathrm{pH}<$ 3. ${ }^{5}$ The cis,cis inversion into the cis,trans isomer was nearly complete within 3 days, giving an estimated half-life time (half of the isomer converted) of 36 hours. Increasing the temperature up to $30^{\circ} \mathrm{C}$ decreased the half-life time to 14 hours. ${ }^{74}$ These findings can also explain why in most biotechnological pathways performed at nearly neutral $\mathrm{pH}$, muconic acid is mainly obtained in its cis,cis conformation. 
a) $\mathrm{pH}<2.9$<smiles>O=C(O)/C=C\C=C\C(=O)O</smiles>

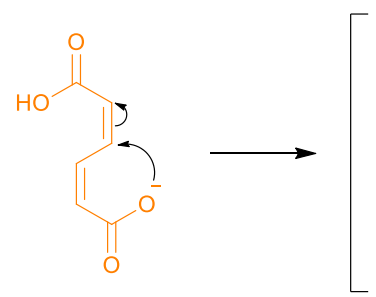

${ }_{O}$
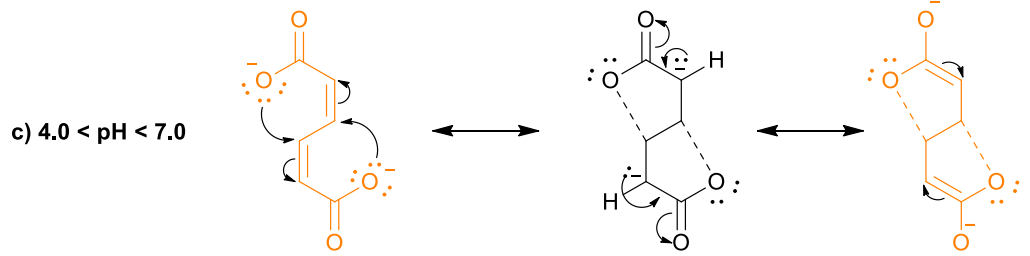

Fig. 6 - The proposed mechanism by Carraher et al. for the isomerization of ccMA into the ctMA at low, middle, and high $\mathrm{pH}$ values (respectively from a to c) in $\mathrm{H}_{2} \mathrm{O}$ or $\mathrm{D}_{2} \mathrm{O} .^{2}$ Reproduced and adapted from ref. 2 with permission from RSC, copyright 2017.

In the previous paragraph, the isomerization routes described use pure ccMA feedstock. However, when cis,cis isomer is produced by biotechnological means, an additional purification step is required prior to isomerization. Alternatively, the in-situ isomerization reactions can be carried out in the fermenter to directly produce ctMA, which can be purified easier than the ccMA due to its better solubility in organic solvents, as shown by Bui et al. ${ }^{13}$ Muconic acid has been produced at a neutral $\mathrm{pH}$ at which there are essentially no spontaneous (or uncatalyzed) isomerization reactions. In order to obtain ctMA, the $\mathrm{pH}$ of the broth after a certain titer was achieved, was adjusted to 4 by adding sulfuric acid, and the solution was then heated to $60^{\circ} \mathrm{C}$ for 3.5 hours (Table 3). Total ccMA (from muconate at low pH) conversion was obtained with a selectivity of nearly $75 \%$ with Mlac as the main side product.

In summary, with the exception of the possible formation of muconolactones, the first isomerization of the cis,cis isomer into the cis,trans form is shown to be spontaneous at appropriate $\mathrm{pH}$ values in water. The trans,trans isomer was never observed in the aforementioned conditions, even after further heating and/or increasing reaction time, indicating that the second isomerization requires harsher chemical activation.

\section{Isomerization of cis,cis and cis, trans muconic isomers into the trans, trans form}

So far, all the proposed isomerization methods for producing ttMA are considered as literature protocols and none of them seem capable to propel to an industrial scale of production. Among these protocols, the most prominent one, in term of productivity values of ttMA, is carried out in the presence of iodine $\left(I_{2}\right)$ under UV light. 2,76 Grundmann was the first to describe the photochemical inversion of ccMA and ctMA into

Table 3 - Summary of the isomerization reactions of cis,cis muconic acid into the cis, trans form

\begin{tabular}{|c|c|c|c|c|c|}
\hline ccMA & Solvents (V) & Conditions & Yield & Side products & Reference \\
\hline $15 \mathrm{~g}$ & $\mathrm{H}_{2} \mathrm{O}(150 \mathrm{~mL})$ & $100^{\circ} \mathrm{C} ; 15 \mathrm{~min} ; \mathrm{pH}<2.5$ & $69 \%$ & Mlac (25\%) & Frost et al. ${ }^{73}$ \\
\hline $3.4 \mathrm{mg} *$ & $\mathrm{D}_{2} \mathrm{O}(5 \mathrm{~mL})^{*}$ & $83^{\circ} \mathrm{C} ; 20 \mathrm{~min} ; \mathrm{pH}<2.5$ & $100 \%$ & - & Tessonier et al..$^{75}$ \\
\hline 3.4 mg* & $\mathrm{D}_{2} \mathrm{O}(5 \mathrm{~mL})^{*}$ & $75^{\circ} \mathrm{C} ; 30 \mathrm{~min} ; \mathrm{pH}<2.5$ & $100 \%$ & - & Carraher et al. ${ }^{2}$ \\
\hline $640 \mathrm{~g}^{* *}$ & $\mathrm{H}_{2} \mathrm{O}(20 \mathrm{~L})$ & $60^{\circ} \mathrm{C} ; 3.5 \mathrm{~h} ; \mathrm{pH}=7^{+}$ & $0 \%$ & $\operatorname{ccMA}^{* *}$ & \multirow[t]{2}{*}{ Bui et al. ${ }^{16,71}$} \\
\hline $380 \mathrm{~g}$ & $\mathrm{H}_{2} \mathrm{O}(20 \mathrm{~L})$ & $60^{\circ} \mathrm{C} ; 3.5 \mathrm{~h} ; \mathrm{pH}=4$ & $75 \%$ & Mlac & \\
\hline $3.4 \mathrm{mg}^{+}$ & $\mathrm{D}_{2} \mathrm{O}(5 \mathrm{~mL})^{*}$ & $22.5^{\circ} \mathrm{C} ; 3 \mathrm{~d} ; \mathrm{pH}<2.5$ & $100 \%$ & - & Matthiesen et al. ${ }^{5}$ \\
\hline
\end{tabular}

* mass was calculated after considering the reaction occurring in $5 \mathrm{~mL}$ solvent (ccMA $=4.8-5.0 \mathrm{mM}$ ). - means absent. ${ }^{* *}$ ccMA $^{2-}$ is the predominant form at this $\mathrm{pH}$ value (no isomerization). 

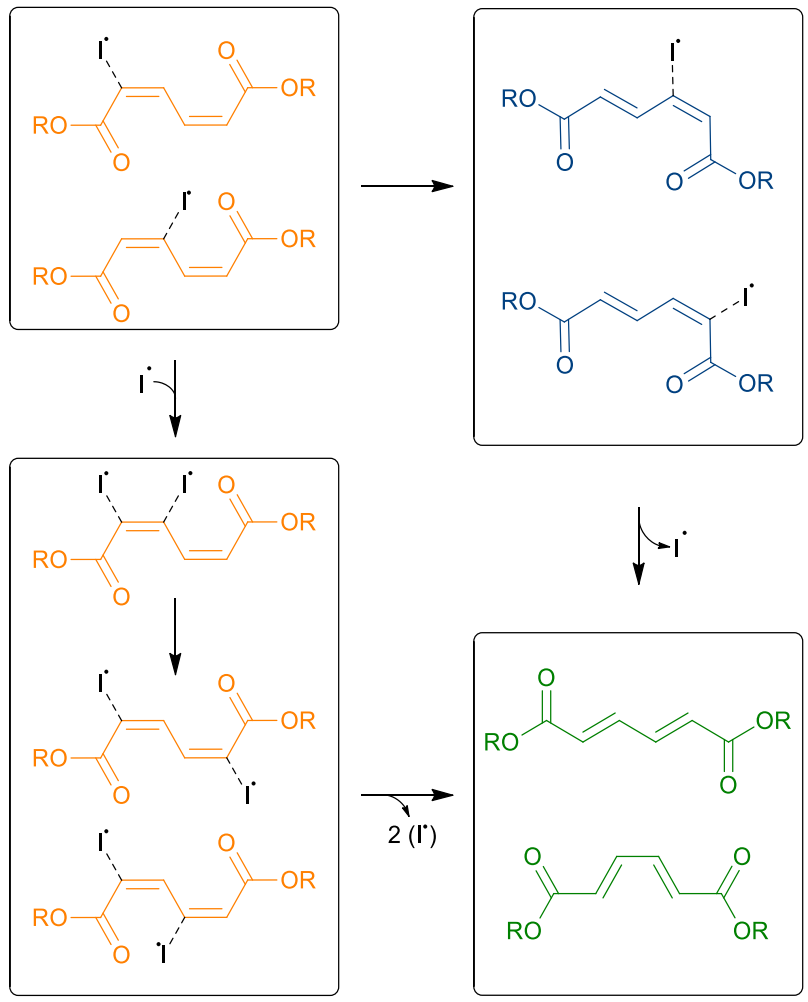

Fig. 7 - The mechanism of the iodine catalysed isomerization reactions of dimethyl muconates through single and double iodine association with olefinic carbons. Reproduced from ref. 72 with permission from Wiley, copyright 2018.

ttMA. ${ }^{36}$ For the rearrangement of ccMA, $100 \mathrm{mg}$ was dissolved in $10 \mathrm{~mL}$ of warm methanol, a trace of iodine was added and then the mixture was irradiated with the unfiltered light of a quartz lamp. After few minutes, the precipitation of the much less soluble ttMA began in crude prisms. The change of ctMA into the ttMA was also observed under the same conditions. ${ }^{36}$ Without iodine, no appreciable formation of ttMA took place, even after several hours of irradiation. ${ }^{36}$ When working in aqueous solutions, the $\mathrm{pH}$ of the solution will be almost 2 (depending on the concentration of $\mathrm{MA}$ ), and the absence of iodine thus leads to the formation of Mlac. ${ }^{15}$ The presence of iodine is thus mandatory to obtain the trans,trans conformation. Settle et al. described the isomerization mechanism by single or double association of radical iodine with one or two olefinic carbons of muconic acid, as shown in Fig. 7 for the case of isomerizing DMM. ${ }^{72}$ The association of a singular iodine atom on the muconic ester catalyzes the isomerization of cis,cis isomer to trans,trans isomer through cis,trans isomer. Simultaneous association of two iodine molecules ( $\mathrm{C} 2 / \mathrm{C} 3$ or $\mathrm{C} 2 / \mathrm{C5}$ ) allows direct isomerization from cis,cis isomer to trans,trans (Fig. 7). The most thermodynamically stable doubleiodine association was observed when iodine is associated on the same double bond ( $22 / C 3)$. This arrangement will not facilitate the bonds rotation to the trans, trans conformation. To perform a simultaneous rotation of both double bonds, one iodine must be associated to each bond as for the arrangement C2/C5. ${ }^{72}$
Table 4 summarizes the results of the different isomerization routes from ccMA and ctMA isomers into ttMA. Frost et al. ${ }^{73}$ have reported the isomerization of ccMA in presence of iodine and acetonitrile as solvent at $82^{\circ} \mathrm{C}$ (boiling point of acetonitrile). $80 \%$ of ttMA was obtained after 36 hours of reaction. The same yield was obtained after 11 hours when using ctMA in the same conditions (low energy barrier). Using THF as a solvent, the isomerization reaction of ctMA can occur at $66^{\circ} \mathrm{C}$ (boiling point of THF) and produce $62 \%$ of the ttMA after 2 hours (Table 4 ). The authors also reported the formation of $84 \%$ of ttMA at room temperature after 5 hours reaction in THF. ${ }^{73}$ Settle et al. investigated the iodine-catalyzed reaction of cis,cis-dimethyl muconate(DMM) in methanol. After 1 hour at room temperature, full conversion was achieved, giving 95\% of ttDMM and $5 \%$ of ctDMM. ttDMM was easily recovered due to its low solubility in methanol ( $\approx 1.5 \mathrm{~g} / \mathrm{L}$ ). ${ }^{72}$ In comparison to MA, muconic esters show a better selectivity towards isomerization which can be explained by the role of ester functionalities in countering lactonization reactions. Despite the good performance obtained in a short time, the restrictions of this method, i.e. limiting feed solutions to $10 \mathrm{wt} . \%$ of muconic acid, place serious constraints on propelling the process into the industrial realm. ${ }^{2}$

Bui et al. patented isomerization technologies based on using hydrogenation catalysts such as $\mathrm{Pd} / \mathrm{C}$ under reflux of methanol. ${ }^{71}$ After 1 hour of reflux in $50 \mathrm{~mL}$ methanol and a catalytic amount of $\mathrm{Pd} / \mathrm{C}$ catalyst (Catalyst/MA molar ratio $=$ $1 / 20), 0.8 \mathrm{~g}$ of ttMA was obtained from $1.0 \mathrm{~g}$ of ccMA. A similar yield was obtained when using the cis,trans isomer. While noble metals are excellent de/hydrogenation catalysts, their high cost makes them less attractive for the isomerization step, especially at such high $\mathrm{Pd} / \mathrm{MA}$ loadings.

Carraher et al. investigated catalyst-free isomerization of $3 \mathrm{mg}$ (4.2 mM) of muconic acid in $5 \mathrm{~mL}$ of different non-polar, polar protic and polar aprotic solvents (acetone, toluene, acetonitrile, THF, ethyl acetate, propan-2-ol, triethylamine, methanol, DMSO and hexanol) at $75^{\circ} \mathrm{C} .^{2}$ The role of the solvent on the isomerization reaction was complex and could not be described in terms of polar and protic properties. In the light of table 1 , polar solvents were selected to allow dissolving a large amount of muconic acid. In addition, protic solvents were avoided to prohibit the lactones from forming. However, Mlac still the major product obtained in most of the solvents (Table 4), e.g. toluene (nonpolar), acetone (polar aprotic), propanol (polar protic), and others. Furthermore, after 2 weeks in triethylamine (polar aprotic), a severe degradation of muconic acid was observed. Quite surprisingly, DMSO was the only solvent in which the trans, trans isomer was observed as a major product (yield $=54 \%$ ). These results revealed the complex role of the solvent that cannot be simply described in terms of polar/nonpolar or protic/aprotic properties. $^{2}$ A future investigation into the mechanism of the isomerization reaction in DMSO may provide important insights about the formation of ttMA. The effect of solvent polarity on the relative proton donating ability may also provide useful insights into this phenomenon. It should be mentioned that the isomerization reaction in DMSO is highly sensitive to the concentration of 


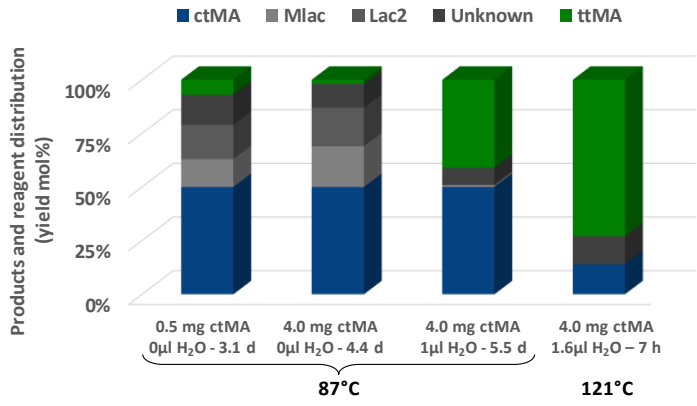

Fig. 8 - Yields of the different isomerization products of 0.5 and $4.0 \mathrm{mg}$ of ctMA in $0.6 \mathrm{~mL}$ DMSO-d6 with and without water adding. $d=$ days. Based on data collected from ref. 75 .

muconic acid in the solution, as Tessonnier et al showed as well. ${ }^{75}$ For a concentration value of $5.5 \mathrm{mM}$ and a conversion of $50 \%$, only $7 \%$ of ttMA was obtained while $13 \%$ of Mlac and $16 \%$ of muconic dilactone (Lac2 - see structure Fig. 11) were produced (Table 4). Increasing the concentration up to $45 \mathrm{mM}$ decreases the yield of the obtained trans,trans isomer $(2 \%)$ in comparison to $19 \%$ Mlac and $18 \%$ of Lac2. At a more industrially relevant concentrations (i.e. $2 \mathrm{M}$ of $\mathrm{MA}$ ), primarily Mlac was obtained after a full conversion with no indication of ttMA. ${ }^{75}$ New or improved isomerization processes should be adapted to high concentrations indeed, for feasibility in upscaling and commercial relevance.

For the same aim of providing the trans,trans isomer, Tessonier et al. patented (i) the effect of adding different amounts of water in DMSO during the isomerization process, (ii) the use of a homogenous Lewis acid catalyst $\left(\mathrm{AlBr}_{3}\right)$, and (iii) the effect of introducing inorganic salts capable to bind to carboxylate functionalities. ${ }^{75}$ In the first substudy (i), the authors studied the isomerization reaction of the $48 \mathrm{mM}$ of ctMA in DMSO at $87^{\circ} \mathrm{C}$ (Table 4 and Fig. 8). ${ }^{75}$ Microliter amounts of water were added to obtain a ratio of $\mathrm{H}_{2} \mathrm{O}$ :MA between 0.1 and 15.5. Results show the existence of an optimal range in which the ttMA is

Table 4 - Summary of the isomerization reactions of cis,cis and cis,trans isomers into the trans,trans form.

\begin{tabular}{|c|c|c|c|c|c|c|}
\hline \multicolumn{2}{|c|}{ ccMA or ctMA } & \multirow{2}{*}{$\begin{array}{l}\text { Solvents (volume) } \\
\mathrm{CH}_{3} \mathrm{CN}(35 \mathrm{~mL})\end{array}$} & \multirow{2}{*}{$\begin{array}{l}\text { Conditions } \\
\mathrm{I}_{2}(25 \mathrm{mg}) ; 82^{\circ} \mathrm{C} ; 36 \mathrm{~h}\end{array}$} & \multirow{2}{*}{$\frac{\text { Yield }}{80 \%}$} & \multirow{2}{*}{$\begin{array}{l}\text { Side products } \\
\text { ND }\end{array}$} & \multirow[t]{2}{*}{ References } \\
\hline $0.5 \mathrm{~g}$ & & & & & & \\
\hline & $1.0 \mathrm{~g}$ & $\mathrm{CH}_{3} \mathrm{CN}(35 \mathrm{~mL})$ & $\mathrm{I}_{2}(53 \mathrm{mg}) ; 82^{\circ} \mathrm{C} ; 11 \mathrm{~h}$ & $80 \%$ & ND & \multirow{3}{*}{ Frost et al. ${ }^{73}$} \\
\hline & $10.0 \mathrm{~g}$ & THF (200 mL) & $\mathrm{I}_{2}(200 \mathrm{mg}) ; 66^{\circ} \mathrm{C} ; 2 \mathrm{~h}$ & $62 \%$ & ND & \\
\hline & $19.0 \mathrm{~g}$ & THF (250 mL) & $\mathrm{I}_{2}(160 \mathrm{mg}) ; \mathrm{RT} ; 5 \mathrm{~h}$ & $84 \%$ & ND & \\
\hline $0.2 \mathrm{~g}^{*}$ & & $\mathrm{CH}_{3} \mathrm{OH}(10 \mathrm{~mL})$ & $\mathrm{I}_{2}(10 \mathrm{mg}) ; \mathrm{RT} ; 1 \mathrm{~h}$ & $95 \% *$ & ctDMM 5\% & Settle et al. ${ }^{72}$ \\
\hline \multirow[b]{2}{*}{$1.0 \mathrm{~g}$} & \multirow[t]{2}{*}{$1.0 \mathrm{~g}$} & $\mathrm{CH}_{3} \mathrm{OH}(50 \mathrm{~mL})$ & $5 \% \mathrm{Pd} / \mathrm{C} ; 65^{\circ} \mathrm{C} ; 1 \mathrm{~h}$ & $80 \%$ & ND & \multirow{2}{*}{ Bui et al. ${ }^{71}$} \\
\hline & & $\mathrm{CH}_{3} \mathrm{OH}(50 \mathrm{~mL})$ & $5 \% \mathrm{Pd} / \mathrm{C} ; 65^{\circ} \mathrm{C} ; 1 \mathrm{~h}$ & $80 \%$ & ND & \\
\hline $3.0 \mathrm{mg}$ & & Triethylamine (5 mL) & $75^{\circ} \mathrm{C} ; 14 \mathrm{~d}$ & $0 \%$ & Degradation & \multirow{10}{*}{ Carraher et al. ${ }^{2}$} \\
\hline $3.0 \mathrm{mg}$ & & Toluene $(5 \mathrm{~mL})$ & $75^{\circ} \mathrm{C} ; 14 \mathrm{~d}$ & $0 \%$ & Mlac & \\
\hline $3.0 \mathrm{mg}$ & & Acetone $(5 \mathrm{~mL})$ & $75^{\circ} \mathrm{C} ; 14 \mathrm{~d}$ & $0 \%$ & Mlac & \\
\hline $3.0 \mathrm{mg}$ & & Acetonitrile (5 mL) & $75^{\circ} \mathrm{C} ; 14 \mathrm{~d}$ & $0 \%$ & Mlac & \\
\hline $3.0 \mathrm{mg}$ & & 2-Propanol (5 mL) & $75^{\circ} \mathrm{C} ; 14 \mathrm{~d}$ & $<5 \%$ & Mlac & \\
\hline $3.0 \mathrm{mg}$ & & Methanol (5 mL) & $75^{\circ} \mathrm{C} ; 14 \mathrm{~d}$ & $<5 \%$ & Mlac & \\
\hline $3.0 \mathrm{mg}$ & & Hexanol (5 mL) & $75^{\circ} \mathrm{C} ; 14 d$ & $<5 \%$ & Mlac & \\
\hline $3.0 \mathrm{mg}$ & & $\mathrm{THF}(5 \mathrm{~mL})$ & $75^{\circ} \mathrm{C} ; 14 d$ & $<5 \%$ & Mlac & \\
\hline $3.0 \mathrm{mg}$ & & Ethyl Acetate $(5 \mathrm{~mL})$ & $75^{\circ} \mathrm{C} ; 14 \mathrm{~d}$ & $<5 \%$ & Mlac & \\
\hline \multirow[t]{12}{*}{$3.0 \mathrm{mg}$} & & DMSO-d6 $(5 \mathrm{~mL})$ & $75^{\circ} \mathrm{C} ; 14 \mathrm{~d}$ & $54 \%$ & Mlac & \\
\hline & $0.5 \mathrm{mg}$ & DMSO-d6 (0.6 mL) & $87^{\circ} \mathrm{C} ; 3.1 \mathrm{~d}$ (c. $\left.50 \%\right)$ & $7 \%$ & ctMA 50\% & \multirow{15}{*}{ Tessonier et al. ${ }^{75}$} \\
\hline & & & & & Mlac 13\% & \\
\hline & & & & & Lac2 16\% & \\
\hline & $4.0 \mathrm{mg}$ & DMSO-d6 (0.6 mL) & $87^{\circ} \mathrm{C} ; 4.4 \mathrm{~d}$ (c. $\left.50 \%\right)$ & $2 \%$ & ctMA 50\% & \\
\hline & & & & & Mlac 19\% & \\
\hline & & & & & Lac2 18\% & \\
\hline & $4.0 \mathrm{mg}$ & DMSO-d6 (0.6 mL) & $1 \mu \mathrm{L} \mathrm{H}_{2} \mathrm{O} ; 87^{\circ} \mathrm{C} ; 5.5 \mathrm{~d}$ (c. $\left.50 \%\right)$ & $41 \%$ & Mlac 9\% & \\
\hline & $4.0 \mathrm{mg}$ & DMSO-d6 (0.6 mL) & $1.6 \mu \mathrm{l} \mathrm{H}{ }_{2} \mathrm{O} ; 121^{\circ} \mathrm{C} ; 7 \mathrm{~h}$ & $73 \%$ & ctMA $14 \%$ & \\
\hline & $3.0 \mathrm{mg}$ & $\mathrm{CD}_{3} \mathrm{CN}(0.6 \mathrm{~mL})$ & $75^{\circ} \mathrm{C} ; 3 \mathrm{~h}$ & $0 \%$ & Mlac & \\
\hline & $3.0 \mathrm{mg}$ & $\mathrm{CD}_{3} \mathrm{CN}(0.6 \mathrm{~mL})$ & $\mathrm{AlBr}_{3}(1.2 \mathrm{mg}) ; 75^{\circ} \mathrm{C} ; 3 \mathrm{~h}$ & $40 \%$ & ctMA $20 \%$ & \\
\hline & & & & & Lac2 40\% & \\
\hline \multirow[t]{5}{*}{$0.4 \mathrm{mg}$} & & $\mathrm{D}_{2} \mathrm{O}(0.6 \mathrm{~mL})$ & $\mathrm{La}_{\mathrm{aq}}{ }^{3+}\left(67 \mathrm{mg} \mathrm{LaBr} 3.6 \mathrm{H}_{2} \mathrm{O}\right)$ & $53 \%$ & ctMA 9\% & \\
\hline & & & $75^{\circ} \mathrm{C} ; 22 \mathrm{~d} ; \mathrm{pH}=3-4$ & & Mlac 35\% & \\
\hline & $0.4 \mathrm{mg}$ & $\mathrm{D}_{2} \mathrm{O}(0.6 \mathrm{~mL})$ & $\mathrm{La}_{\mathrm{aq}}{ }^{3+}\left(87 \mathrm{mg} \mathrm{LaBr} 3.6 \mathrm{H}_{2} \mathrm{O}\right)$ & $55 \%$ & ctMA $36 \%$ & \\
\hline & & & $90^{\circ} \mathrm{C} ; 10 \mathrm{~d} ; \mathrm{pH}=5$ & & Mlac 9\% & \\
\hline & $25 \mathrm{mg}$ & $\mathrm{H}_{2} \mathrm{O}(50 \mathrm{~mL})$ & $\begin{array}{l}\mathrm{HCOOH}(0.6 \mathrm{~g}) ; \mathrm{Fe} ; \mathrm{E}=-1.72 \\
\mathrm{~V} ; 1 \mathrm{~h}\end{array}$ & $8 \%$ & $\begin{array}{l}\text { ctMA } 60 \% \\
\text { t3HDA } 18 \%\end{array}$ & Matthiesen et al. ${ }^{5}$ \\
\hline
\end{tabular}

* dimethyl muconate (DMM) were used instead of MA. 


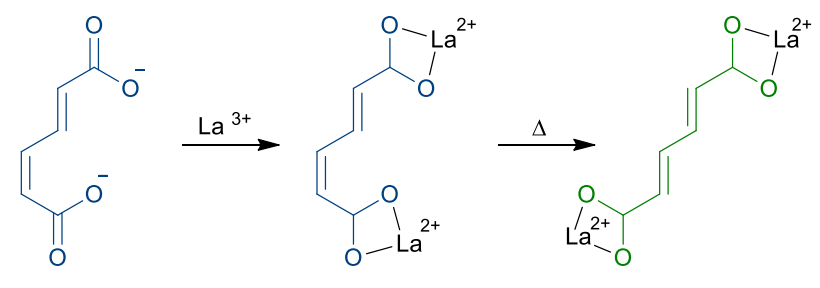

Fig. 9 - Isomerization of the cis, trans muconic acid into the trans, trans isomer using Lanthanum (III) salt.

selectively produced $\left(0.9<\mathrm{H}_{2} \mathrm{O}: \mathrm{MA}<10\right)$. At a ratio value of almost 2 (96.1 $\mathrm{mM}$ of $\mathrm{H}_{2} \mathrm{O}$ ), a dramatic improvement of the selectivity was observed (Fig. 8). At $50 \%$ conversion, $40 \%$ of ttMA (selectivity $=82 \%$ ) was obtained with no more than $2 \%$ of Mlac formed. When heating at $121^{\circ} \mathrm{C}$ for 7 hours in presence of 3.4 equivalents of $\mathrm{H}_{2} \mathrm{O}(1.6 \mu \mathrm{L}), 73 \%$ of ttMA was produced with a selectivity of $84.4 \%$.

Secondly (ii), after an unsuccessful isomerization of $3.0 \mathrm{mg}$ of ctMA in deuterated acetonitrile at $75^{\circ} \mathrm{C}$ and $\mathrm{pH}=5$ (Mlac production), the authors claimed that adding $1.2 \mathrm{mg}$ of $\mathrm{AlBr}_{3}$, a soluble Lewis acid, in the media, can lead to $40 \%$ of ttMA in 3 hours. These findings were explained by the weakening of the $\mathrm{C}=\mathrm{C}$ bonds caused by coordination with the Lewis acid that facilitates rotation along the $\mathrm{C} 2-\mathrm{C} 3$ or $\mathrm{C} 4-5$ axis leading to formation of the thermodynamically preferred trans,trans isomer. This effect of Lewis acid was also reported on carbonyl, in which Lewis acid reduces the electron density on the carbonyl carbon and lowers the energy of the lowest unoccupied molecular orbital. ${ }^{77}$ Conducting the same experiment in DMSO did not give promising results due to the deactivation of the catalyst by its reaction with DMSO and the formation of thiols. ${ }^{75}$ These findings underline the potential of homogenous Lewis acids in the isomerization reaction. In the third attempt (iii), the authors studied the effect of the introduction of inorganic salts (Lanthanum (III) bromide hexahydrate) of which the cation is capable to bind to carboxylate functionalities and thus decreases the intramolecular interactions and potentially favor the isomerization reaction (Fig. 9). Lanthanum (III) was selected notably due to its large binding constants for carboxylates (on the order of $\left.10^{3}-10^{5}\right)^{2,78} .230-290 \mathrm{mM}$ of $\mathrm{La}^{3+}$ were tested with $4.8 \mathrm{mM}$ of ccMA in deuterated water. After 22 days at $75^{\circ} \mathrm{C}$ and a $\mathrm{pH}$ ranging between 3 and 4 , a yield of 53\% of ttMA was obtained (selectivity 58\%). Mlac was obtained as a side product (35\%). Replacing ccMA by ctMA and increasing the temperature up to $90^{\circ} \mathrm{C}$, led to a faster reaction producing $55 \%$ of ttMA in 10 days (selectivity $85 \%$ ). Lanthanum salts are highly sensitive to the $\mathrm{pH}$ value, e.g. for $\mathrm{pH}$ values lower than 3 , there are no carboxylate groups to bind while for $\mathrm{pH}$ values higher than 5.5, the $\mathrm{La}\left(\mathrm{H}_{2} \mathrm{O}\right)_{6}{ }^{3+}$ will transform into $\mathrm{La}(\mathrm{OH})_{n}\left(\mathrm{H}_{2} \mathrm{O}\right)_{6-n}$ which exhibit both lower solubility and smaller binding constants for carboxylate. ${ }^{2,75,79}$ The disadvantage of this method consists on the difficult recovery of ttMA as well as the lower recycling capacity of the soluble Lanthanum catalyst. Recovering the ttMA upon acidification isolated only $24 \%$ of the initial amount of muconic acid. On the other hand, extracting the muconic acid with ethyl acetate recovered $60 \%$ of the muconic acid, but significant losses of the La(III) were observed. ${ }^{79}$ In the three presented substudies, the processes adopted to selectively produce ttMA were performed at practically low concentration of $\mathrm{MA}(<50 \mathrm{mM})$. However, to be more industrially relevant in terms of scale, the concentration of MA in an isomerization process will likely need to be in the order of $2 \mathrm{M} .{ }^{75}$

Recently, the electrocatalytic hydrogenation of muconic acid was studied by Matthiesen et al. in the aim to produce biobased monomers, e.g. trans-3-hexenedioic acid. ${ }^{5}$ ttMA was formed as an intermediate of the electrocatalytic reaction starting from ctMA. $25 \mathrm{mg}$ of ctMA was added to $50 \mathrm{~mL}$ of water solution and $0.26 \mathrm{mM}$ of formic acid (electrolyte). A potential of $-1.72 \mathrm{~V}$ was applied for 1 hour while following conversion and selectivities in time. The study used different metal electrodes, the most promising in term of ttMA production being iron (8\%), copper (7.5\%), and palladium (5\%). In terms of making the target trans3-hexenedioic acid, a lead electrode was better (conversion = $65 \%$, selectivity $=95 \%$ ).

To conclude this part, different attempts have been reported to produce the value-added ttMA from the two other isomeric forms, namely the cis,cis and the cis,trans isomers. The iodine system as well as the $\mathrm{Pd} / \mathrm{C}$ catalyst have shown the highest yield of the desired isomer. However, the limitation in the feed solutions to $10 \mathrm{wt} . \%$ of muconic acid in the case of the iodine system and the high cost of noble metals place serious constraints on propelling these processes into the large scale or commercial realm. By thermal heating of muconic in a screening of different solvents, it was noted that only in DMSO the ttMA was obtained as such, as major product, while the mechanism responsible is not fully understood. Adding water to the mixture may improve the yield of the reaction. Nonetheless, using DMSO as solvent for the acid is a limited solution, since at high concentration of MA ( 2M), no trace of ttMA was observed. The presence of homogenous Lewis acid was found to speed up or facilitate the isomerization in acetonitrile. Regarding the use of lanthanum (III), a decent selectivity to the value-added isomer was overshadowed by its difficult recovery as well as the low recycling capacity of the catalyst (maximum recovery $=60 \%$ ). Finally, Earth-abundant metal, such as $\mathrm{Fe}$ and $\mathrm{Cu}$, have led to the formation of the ttMA in electrocatalytic reaction. A final observation is that the isomerization of muconic esters has only been studied with the iodine system. Since the esters are more soluble and lactonization seems more difficult from esters, isomerization processes starting from esters could be promising.

\section{Transformation of MA into valuable chemicals}

Although muconic acid does not appear in the U.S. Department of energy "Top 10" list of biomass-derived platform chemicals, or its update, it is receiving increasing attention for its use as raw material for value-added products and monomers, e.g. adipic acid, $\varepsilon$-caprolactam, terephthalic acid, hexamethylenediamine...5,80 This section summarizes the transformation pathways of muconic acid into its most valueadded derivates. Unsaturated 3-hexenedioic acids, target in electrochemical hydrogenation, is not covered here anymore. 


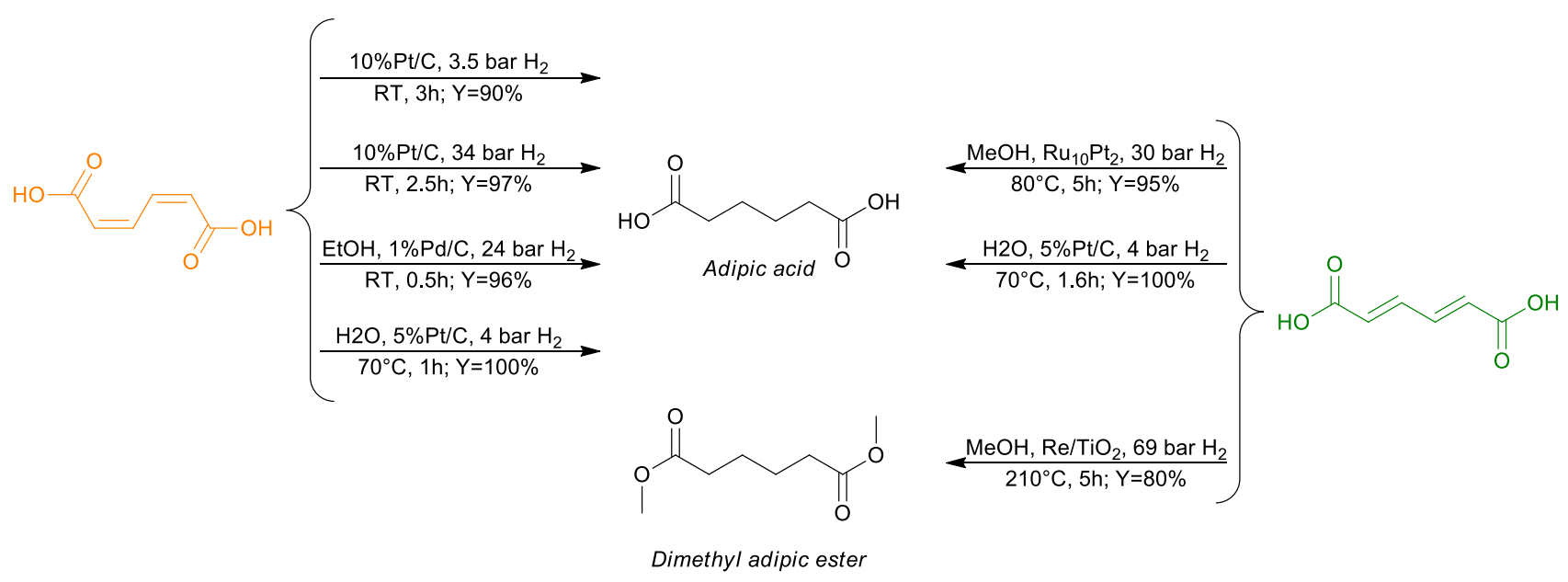

Fig. 10 - Catalytic hydrogenation reaction of muconic acid to adipic acid based on data in references $66,82-85$.

\section{Adipic acid production}

With a market volume of 3.0 million tons per year and an annual demand growth of $3.5 \%$ globally, adipic acid is one of the most produced commodity chemicals (diacids) worldwide. ${ }^{81}$ It has uses as a polymer precursor for nylon 6,6 and different other applications in plastics and lubricants production. ${ }^{81}$ Adipic acid can be obtained by biotechnological pathways from the transformation of glucose or lignin-derived bio-oils (catechol, anisole, guaiacol...). ${ }^{19,62,66,81}$ In chemical pathways, adipic acid can be obtained by nitric acid oxidation of benzene derived cyclohexanol and cyclohexanone. Due to the high toxicity of benzene and the release of $\mathrm{N}_{2} \mathrm{O}$ as a byproduct of the oxidation reaction, new benzene-free pathways were recommended for producing adipic acid. 62,82 In this sense, biotechnologically produced muconic acid offers the possibility to produce adipic acid by hydrogenation e.g. with $\mathrm{Pt} / \mathrm{C}$ catalysts, ${ }^{62,66}$ bimetallic RuPt nanoparticules ${ }^{83}, \mathrm{Pd} / \mathrm{C}$ catalyst ${ }^{84}$ or Re supported over Titania catalysts. 85

Frost et al. have established a biotechnological conversion of Dglucose into ccMA with subsequent catalytic hydrogenation to afford adipic acid. ${ }^{66}$ The culture was maintained at $\mathrm{pH} 6.3$ in order to accumulate the ccMA in absence of the cis,trans isomer. The catalyst, $10 \mathrm{wt}$.\% Pt supported on activated carbon catalyst $(\mathrm{Pt} / \mathrm{C})$ was added to the unpurified culture, and the solution was hydrogenated at 3.5 bar for 3 hours at room temperature. Under these conditions, ccMA was catalytically hydrogenated to adipic acid with $90 \%$ yield (Fig. 10). Niu et al. have also performed in situ production of adipic acid from ccMA in the batch fermenter. ${ }^{62}$ After removing the microbiological cells and protein from the medium, it was pressurized with 34 bar of hydrogen, in presence of a Pt/C catalyst. After 2.5 hours reaction at room temperature, the reduction of ccMA to adipic acid had proceeded in $97 \%$ yield (Fig. 10). ${ }^{62}$ Recently, Vardon et al. studied the activity of $\mathrm{Pd} / \mathrm{C}$ catalysts in the hydrogenation of ccMA into adipic acid. ${ }^{84}$ The reactions were performed by adding $15 \mathrm{mg}$ of $1 \mathrm{wt} \% \mathrm{Pd} / \mathrm{C}$ in a solution of $15 \mathrm{~mL}$ ethanol containing $200 \mathrm{mg}$ of ccMA (a ccMA:Pd mol ratio of 1000). With a hydrogen pressure of 24 bar and 30 minutes at $24{ }^{\circ} \mathrm{C}$ (Fig. 10), the $\mathrm{Pd} / \mathrm{C}$ catalyst showed a high and selective conversion ( $>97 \%$ for both conversion and selectivity). In another work, Vardon et al. compared the turnover frequency (TOF) and the percentage of the leached metal of 8 catalysts in ethanol, namely $1 \% \mathrm{Pd} / \mathrm{C}$, $1 \% \mathrm{Pd} / \mathrm{SiO}_{2}, 1 \% \mathrm{Rh} / \mathrm{C}, 1 \% \mathrm{Rh} / \mathrm{SiO}_{2}, 5 \% \mathrm{Pt} / \mathrm{C}, 5 \% \mathrm{Pt} / \mathrm{SiO}_{2}, 5 \% \mathrm{Ru} / \mathrm{C}$ and $5 \% \mathrm{Ru} / \mathrm{SiO}_{2} .{ }^{70}$ Over all the catalysts, a complete conversion of ccMA into adipic acid was observed at the end of the reaction. The highest TOF were displayed by the catalysts containing Pd (14-23 s $\left.\mathrm{s}^{-1}\right)$ and Rh (7-8 $\left.\mathrm{s}^{-1}\right)$. Despite its high TOF, high metal leaching was identified over Pd catalysts after only 35 minutes of reaction ( 9\% of the Pd leaching from a $1 \%$ $\left.\mathrm{Pd} / \mathrm{SiO}_{2}\right) .{ }^{70}$ Catalysts containing $\mathrm{Pt}$ and $\mathrm{Rh}$ showed less leaching, e.g. $0.16 \%$ for a $1 \% \mathrm{Rh} / \mathrm{C}$ catalyst and $0.03 \%$ of a $5 \% \mathrm{Pt} / \mathrm{C}$ catalyst. Combining high activity and stability for muconic acid hydrogenation reaction, the $1 \% \mathrm{Rh} / \mathrm{C}$ catalyst was considered as the most performant catalyst for batch reactor MA hydrogenation reactions. ${ }^{70}$

The hydrogenation of ttMA into adipic acid was investigated by Thomas et al. using bimetallic ruthenium-platinum nanocatalysts $\left(\mathrm{Ru}_{10} \mathrm{Pt}_{2}\right) .{ }^{83}$ The reaction consists of adding $5 \mathrm{~g}$ of MA in $100 \mathrm{~mL}$ methanol with $50 \mathrm{mg}$ of catalyst and 30 bars of hydrogen, to react at $80^{\circ} \mathrm{C}$ for 5 hours (Fig. 10). High conversion was observed (>90\%), and the selectivity towards adipic acid formation was almost $95 \%$. Succinic and glucaric acids were obtained as side products of the reaction. ${ }^{83} \mathrm{~A}$ comparison of the activity of cCMA and ttMA in hydrogenation reactions to produce adipic acid was achieved by Capelli et al. ${ }^{86}$ Hydrogenation reactions were realized by adding $0.01 \mathrm{~g}$ of $5 \%$ $\mathrm{Pt} / \mathrm{C}$ catalyst in $10 \mathrm{~mL}$ of aqueous solution with $0.1 \mathrm{~g}$ of the selected sodium muconate isomer. After 1 hour at $70^{\circ} \mathrm{C}$ under 4 bar $\mathrm{H}_{2}$, total conversion was observed when using both isomers. However, selectivity behaviors were slightly different. When using the cis,cis muconate isomer $100 \%$ of adipic acid was produced after $1 \mathrm{~h}$, confirming a total hydrogenation for both double bonds. While for trans,trans muconates the total hydrogenation appears to be less spontaneous since almost $25 \%$ of 2 -hexenedioc acid remains after $1 \mathrm{~h}$. After 40 more 
minutes total hydrogenation was achieved and a of $100 \%$ of adipic acid was obtained (Fig. 10). ${ }^{86}$ These findings were also validated by Matthiesen et al., who calculated the free energies associated to total hydrogenation reactions of ccMA and ttMA into adipic acid. ${ }^{5}$ With a difference of $25.1 \mathrm{~kJ} / \mathrm{mol}$, the hydrogenation of ccMA ( $\left.\Delta \mathrm{G}_{\text {gas }}=-163.6 \mathrm{~kJ} / \mathrm{mol}\right)$ appears to be more spontaneous than in the case of ttMA $\left(\Delta G_{\text {gas }}=-138.5\right.$ $\mathrm{kJ} / \mathrm{mol}) .^{5}$ ttMA was also converted into the dimethyl ester of adipic acid using supported Re catalysts. ${ }^{85}$ The one pot esterification/hydrogenation reaction occurred at $210^{\circ} \mathrm{C}$ in methanol under 69 bar of $\mathrm{H}_{2}$. After 5 hours, almost $90 \%$ of the muconic acid (or ester formed) were converted into three main products, namely the dimethyl esters of (1) hexanedioic acid (adipic acid), (2) 2-hexenedioic acid, and (3) 2,4-hexadienedioic acid. The presence of compounds (2) and (3) points out the difficulty to achieve a total hydrogenation of the muconic esters in comparison to the practically total hydrogenation obtained with MA at lower temperature. The authors investigated the role of the support on the selectivity towards the desired product, explicitly dimethyl adipate. When supported over alumina, ZSM-5 zeolite or mesoporous silica SBA-15, Re hydrogenation sites exhibited low rates and only $30 \%$ of the adipate ester was formed. Significant hydrogenation activity was observed when supporting $\mathrm{Re}$ on $\mathrm{TiO}_{2}$, and $88 \%$ of the desired adipic acid dimethyl ester was identified in the reaction products (Fig. 10). These findings were explained by the low loading and high distribution of Re over $\mathrm{TiO}_{2}$ as well as by the weak binding of $\mathrm{Re}$ to the $\mathrm{TiO}_{2}$ support that led to a high ratio of reduced Re sites on the surface, which improved the hydrogenation activity. ${ }^{85}$

The described methods show that the transformation of MA to adipic acid is almost quantitative, while the transformation of muconic esters into adipic esters shows a lower yield (80\%) and require higher temperature. Economic attractiveness of this route to adipic acid from the biotechnological produced MA will thus mostly rely on the efficiency and cost of the biotechnological synthesis of MA, and the separation/purification steps for isolating MA or adipic acid from the culture, and not on isomerization processes.

\section{Lactones: Muconolactone, dilactone and $\varepsilon$ - caprolactam production}

Muconic acid can perform cyclisation reactions by intramolecular attack of one of the carboxylic acid groups on the carbon in the $\mathrm{C} 4$ position to form a five-membered ring lactone e.g. muconolactone (Mlac) and tetra-hydrofuro[3,2b]furan-2,5-dione, a dilactone (Lac2) (Fig. 11). Mlac can be converted into levulinic after hydrolysis and other steps,or oxidized to give maleic acid, ${ }^{87}$ while Lac 2 can be polymerized by ring opening reactions into muconic lactone polymers. ${ }^{7}$ While valorization routes via Mlac and Lac2 remain questionable at this time, the seven-membered ring $\varepsilon$-caprolactam can be also obtained from muconic acid, after its conversion into adipamide and the intramolecular attack of one amide group on the other.
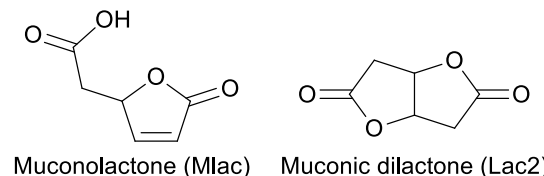

Muconolactone (Mlac) Muconic dilactone (Lac2)

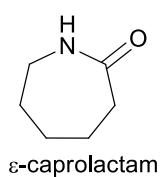

Fig. 11 - Muconolactone, dilactone and $\varepsilon$-caprolactam structures.

$\varepsilon$-caprolactam is the main precursor in the ring opening polymerization to produce nylon $6 .{ }^{14}$

\section{Muconolactone and dilactone}

Elvidge et al. were the first to study lactonization reactions of the two known muconic isomers at the time (1950), namely cis, cis and trans, trans MA. ${ }^{87}$ Mlac was obtained after 24 hours of a reaction of $15 \mathrm{~g}$ of ccMA with sulfuric acid $(60 \mathrm{~mL}-95 \%$ purity) and water $(20 \mathrm{~mL})$ at room temperature $(80 \%$ yield). The formation of an isomeric non-acidic byproduct was also recognized and attributed to the muconic dilactone. Milan et al. have patented the ring opening polymerization reaction of the dilactone when heating at $180^{\circ} \mathrm{C}$ under argon for 4 hours 7 obtaining a poorly characterized muconic lactone polymer. A negative control, i.e. a failing to obtain the lactonization reaction for ttMA was reported by Elvidge et al., even when
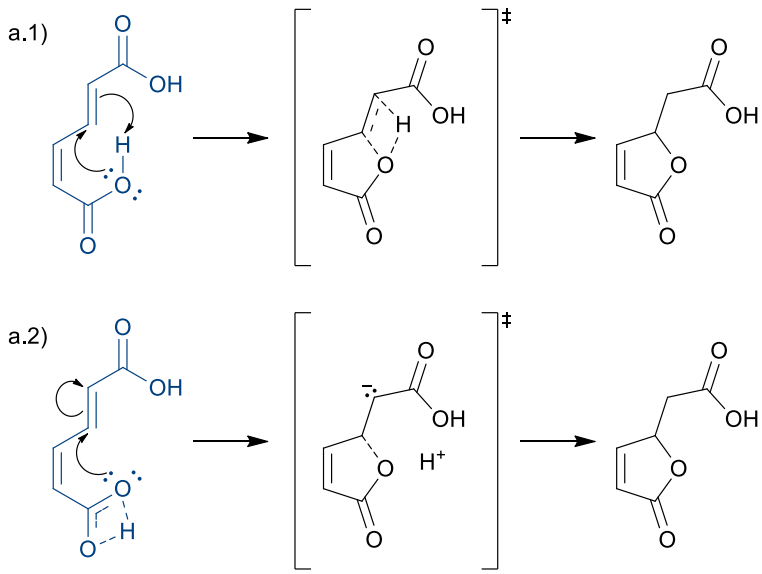

b)

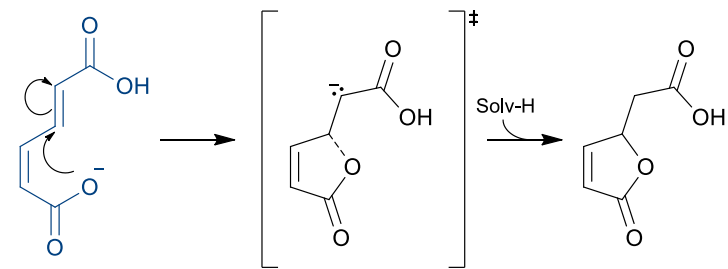

c)

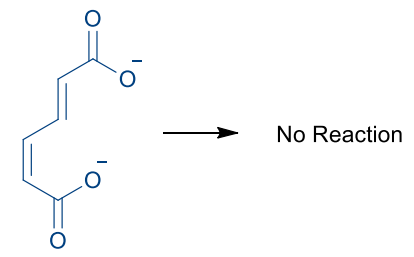

Fig. 12 - Ring closing of ctMA to Mlac through unimolecular cyclisation reaction at low (a), middle (b), and high $\mathrm{pH}$ values (c). ${ }^{*}$ Solv-H refers to protic solvents. Reproduced from ref. 2 with permission from RSC, copyright 2017. 
increasing the temperature or the acidity by adding a mixture of acetic acid and hydrogen chloride. ${ }^{87}$ The stability of this isomer with respect to the lactonization reaction is related to it its spatial conformation that prevents the intramolecular attack of the carboxylic on the interior C4 adjacent carbon. Carraher et al. investigated the mechanism of the lactonization reaction while studying muconic acid isomerization. ${ }^{2}$ They show that lactonization can occur once the cis,cis isomer is inverted into the cis,trans conformation, and also that lactonization is sensible to $\mathrm{pH}$. At $\mathrm{pH}$ values lower than the second $\mathrm{pKa}$ value of the ctMA $\left(\mathrm{pKa}_{2}=4.0\right)$, mainly ctMA and cis, trans monomuconates (ctMA-) are present in the media allowing, after heating, the formation of muconolactone by an intramolecular attack of the cis $\mathrm{COOH}$ and $\mathrm{COO}^{-}$groups, respectively, on the interior $\mathrm{C} 4$ adjacent carbon as shown in Fig. 12-a and Fig. 12-b. At $\mathrm{pH}$ values higher than 5 , the authors show that lactonization does not occur. ${ }^{2}$

\section{$\varepsilon$-caprolactam}

$\varepsilon$-caprolactam is used as monomer for nylon 6 via catalytic ring opening polymerization. ${ }^{14}$ Its global market is in a continuous increase in the last years and it was over 4.0 million tons in 2012. ${ }^{14}$ The dominating production process for $\varepsilon$-caprolactam relies on the conversion of cyclohexanone to cyclohexanone oxime that is converted by the Beckmann rearrangement into $\varepsilon$-caprolactam. ${ }^{88}$ In recent years, alternative pathways to produce $\varepsilon$-caprolactam from renewable biobased feedstock have been introduced, where the use of MA has been highlighted. The indirect way of transforming MA into $\varepsilon$ caprolactam consists on the hydrogenation of muconic acid in a first step to obtain adipic acid as detailed above. In a second step, adipic acid can be reacted with ammonia to form adipamide that can be catalytically (e.g. $\mathrm{Ru} / \mathrm{Al}_{2} \mathrm{O}_{3}$ ) converted under $\mathrm{H}_{2}$ pressure to $\varepsilon$-caprolactam, via ring closing reaction after the intramolecular attack of one amide group on the other. ${ }^{89}$ However, a screening of the conditions of the one pot conversion of ttMA into $\varepsilon$-caprolactam has been recently patented by Frost et al. ${ }^{89}$. The study of different catalyst types, in dioxane at $250^{\circ} \mathrm{C}$ under 3.4 bar of $\mathrm{NH}_{3}$ and 34 bar of $\mathrm{H}_{2}$, has shown important yield of $\varepsilon$-caprolactam over both $5 \% \mathrm{Pd} / \mathrm{Al}_{2} \mathrm{O}_{3}$ (44\%) and $5 \% \mathrm{Ru} / \mathrm{Al}_{2} \mathrm{O}_{3}(58 \%)$. Combining both catalysts $(0.7$ mol\% of $5 \% \mathrm{Ru} / \mathrm{Al}_{2} \mathrm{O}_{3}$ with $0.33 \mathrm{~mol} \%$ of $5 \% \mathrm{Pd} / \mathrm{Al}_{2} \mathrm{O}_{3}$ ), showed similar efficiency as obtained by $5 \% \mathrm{Ru} / \mathrm{Al}_{2} \mathrm{O}_{3}$. In term of reaction time and final yield of $\varepsilon$-caprolactam, the use of dioxane as solvent was better: a higher yield of $\varepsilon$-caprolactam was obtained than with water, methanol or DMSO. Moreover, the authors underlined that increasing the reaction temperature as well as the catalyst amount strongly led to more $\varepsilon$-caprolactam while, the variation of the $\mathrm{H}_{2}$ pressure, between 14 and 138 bar, didn't affect the yield. Interestingly, the activity of the three MA isomers was compared by adding $5 \%$ of $\mathrm{Pd} / \mathrm{Al}_{2} \mathrm{O}_{3}$ catalyst in dioxane with $70 \mathrm{mM}$ of a given $\mathrm{MA}\left(250^{\circ} \mathrm{C}\right.$, $2 \mathrm{~h}$, first under 3.4 bar of $\mathrm{NH}_{3}$ and then 34 bar of $\mathrm{H}_{2}$ ). Almost $78 \%$ of conversion $(\mathrm{X})$ occurred regardless of the used isomer (Fig. 13). However, the selectivity towards $\varepsilon$-caprolactam differs with the geometrical conformation of muconic isomers. Some of the intermediates of this one pot reaction can be: muconic amide isomers, unsaturated muconic amides (cis or trans hex-2enediamide or its rearranged cis or trans hex-3-enediamide), 1,6-hexanediamine and adipamide (Fig. 13). The yields $(\mathrm{Y})$ of produced $\varepsilon$-caprolactam and hexamethyleneimine were reported by the authors, as presented in Fig. $13 .{ }^{89}$ For the same conversion, ccMA and ctMA produced comparable amounts of results $\varepsilon$-caprolactam, while ttMA was somewhat less selective. In this one pot transformation, ring closing reactions to produce $\varepsilon$-caprolactam and hexamethyleneimine may be performed prior to hydrogenation or after first or second hydrogenation reactions. When performed prior to hydrogenation, ring closing reactions will be affected by the geometry of the used muconic amide isomer, which may explain the lower yield of cyclic compounds ( $44 \% \varepsilon$-caprolactam and $6 \%$ hexamethyleneimine) obtained for the trans,trans isomer. The cis,cis isomer, which presents the most favorable geometry for cyclisation reactions, has shown the highest produced yield for both cyclic

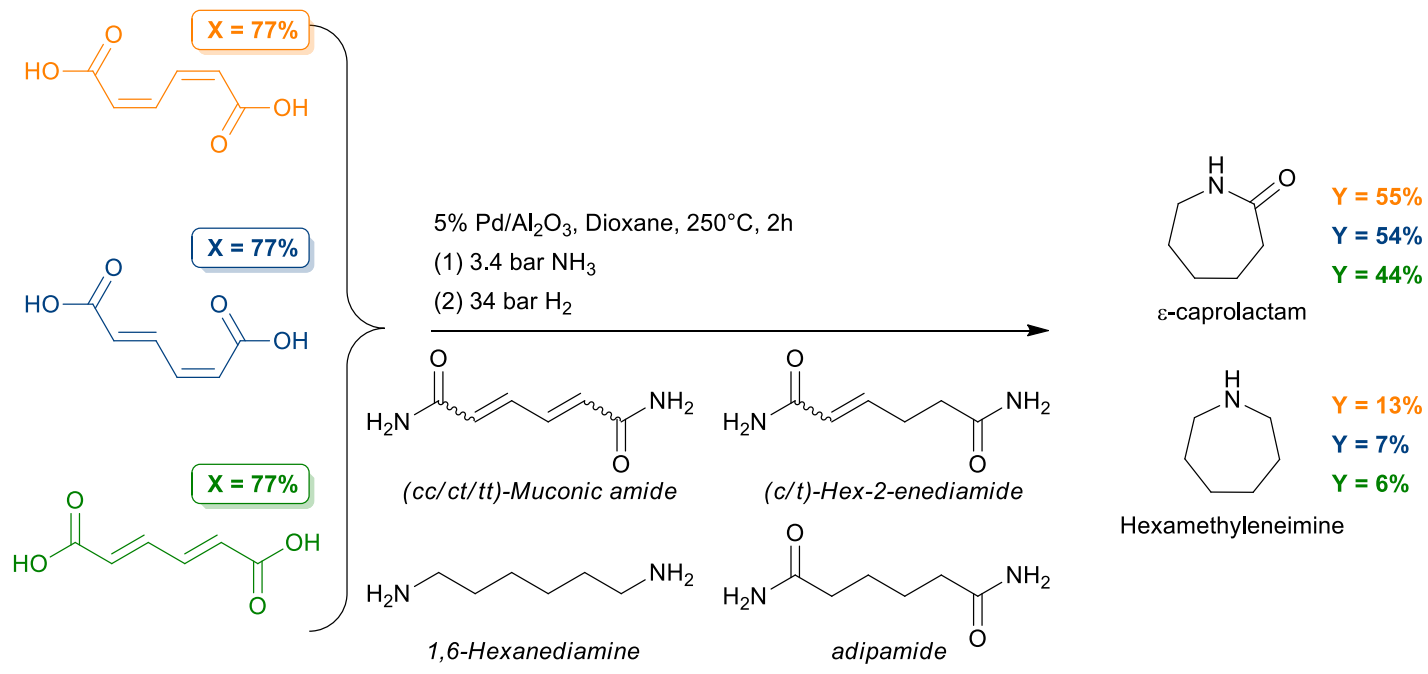

Fig. 13 - $\varepsilon$-caprolactam production from the three isomers of MA. $\mathrm{X}$ refers to the conversion values of muconic acid and $\mathrm{Y}$ refers to the yield of produced $\varepsilon$-caprolactam and adipamide. Based on data collected from ref. 89. 

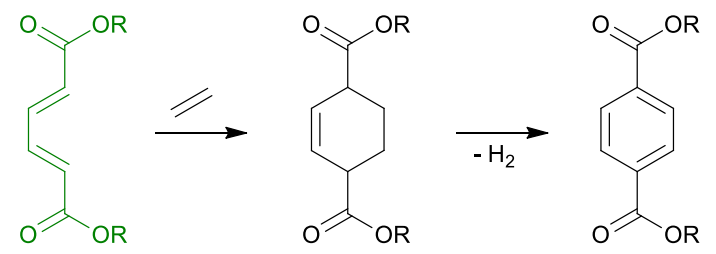

ttMA (or ester)

Tetrahydro TPA (or ester)

TPA (or ester)

Fig. 14 - Trans,trans muconic acid (or esters) transformation into terephthalic acid (or esters) via Diels-Alder and subsequent dehydrogenation. $\mathrm{R}: \mathrm{H}, \mathrm{CH}_{3}, \mathrm{C}_{2} \mathrm{H}_{5}$, and other alkyl chains.

compounds $(68 \%$ in comparison to $61 \%$ and $50 \%$ for ct and tt isomers, respectively).

\section{Terephthalic acid and terephthalates}

Another use of muconic acid is the production of terephthalic acid (TPA) by performing the Diels-Alder addition reaction with ethylene (the dienophile). The global consumption of terephthalic acid was 47 million tons in 2012 and this market was expected to grow with an average of $6 \%$ per year. ${ }^{76}$ Terephthalic acid is primarily used as a co-monomer with ethylene glycol to produce polyethylene terephthalate (PET) by polycondensation. By changing the glycol chains, other polyesters can be produced from terephthalic acid. These polyesters have ample application in the production of plastic containers, fibers, films... The major chemical pathways to TPA is known as the Amoco process. ${ }^{90,91}$ It consists on the oxidation of $25 \%$ of para-xylene in glacial acid under air at $175-225^{\circ} \mathrm{C}$ and 15-30 bar. Manganese and cobalt salts are used as catalysts and sodium bromide or other bromide compounds can be added as promoters. ${ }^{92}$ After an hour of reaction time, $98 \%$ of para-xylene is converted to produce $95 \mathrm{~mol} \%$ of TPA. However, this product requires additional purification steps before being used in polymer condensation. ${ }^{76}$ The production of TPA using the aforementioned pathway relay on petroleum derivates since para-xylene is mainly produced from naphtha. In this sense, alternative renewable and biobased pathways are being developed to offer petroleum independency. ${ }^{93}$ Three possible biomass-based pathways have been proposed as reviewed by Collias et al. (1) the production of biobased para-xylene, (2) the substitution of petroleum-derived para-xylene by other intermediates and reaction routes to TPA, e.g. muconic acid, and finally ( 3 ) the direct production, without intermediates, of TPA from carbohydrates. ${ }^{76}$

From the three isomers of muconic acid, only ttMA can perform the Diels-Alder reaction in the role of diene, as shown in Fig. 14. 6,94 The steric effect over ccMA and ctMA prohibits the DielsAlder reaction using these isomers. Frost et al. studied the onestep isomerization/Diels-Alder reaction of the cis,trans isomer. In a Parr reactor $8.2 \mathrm{~g}$ of ctMA was mixed with iodine in $120 \mathrm{~mL}$ THF at $160^{\circ} \mathrm{C}$, under a pressure of 17.4 bar of ethylene. ${ }^{95}$ After $25 \mathrm{~h}, 75 \mathrm{~mol} \%$ of tetrahydro terephthalic acid was recovered, showing a successful one pot isomerization of ctMA into ttMA, followed by the cycloaddition of the latter with ethylene. In another reaction, $2.1 \mathrm{~g}$ of ttMA were suspended in $120 \mathrm{~mL} \mathrm{H} \mathrm{H}_{2} \mathrm{O}$ under ethylene atmosphere $\left(18.6\right.$ bar at $\left.23^{\circ} \mathrm{C}\right)$. After 3 days reaction at $150^{\circ} \mathrm{C} 34 \mathrm{~mol} \%$ of tetrahydro terephthalic acid were obtained. Afterwards, terephthalic acid could be obtained upon catalytic dehydrogenation of tetrahydro terephthalic acid, using $\mathrm{Pt} / \mathrm{C}$ at $150^{\circ} \mathrm{C}$ (yield $=55 \mathrm{~mol} \%$ ), or other dehydrogenation catalysts. ${ }^{93,95,96}$

Better yields are achieved when esterification is done prior or parallel to the cycloaddition, mainly due to the higher solubility of muconic esters (Table 1). Lu et al. investigated the combination of esterification, Diels-Alder cycloaddition and dehydrogenation of ttMA. ${ }^{6}$ The esterification and the DielsAlder cycloaddition reactions were performed in ethanol and under ethylene pressure ( $10-30 \mathrm{bar}$ ) at $200^{\circ} \mathrm{C}$ in presence of silicotungstic acid catalyst. Among the products, tetrahydro terephthalic acid was obtained in addition to ttDEM. The reaction time profile data indicated the sequential order of esterification and Diels-Alder cycloaddition (mono- and di-ester of ttMA are formed prior to cycloaddition). At 30 bar, $98 \%$ of the tetrahydro form was produced. In a second step, the reaction mixture was directly used as feedstock of the dehydrogenation reaction. The reaction was conducted under $\mathrm{N}_{2}$ pressure at $200^{\circ} \mathrm{C}$, using different catalysts $(30 \% \mathrm{Ni} / \mathrm{C}, 30 \%$ $\mathrm{Cu} / \mathrm{C}, 2.5 \% \mathrm{Ru} / \mathrm{C}, 2.5 \% \mathrm{Pt} / \mathrm{C}$, and $2.5 \% \mathrm{Pd} / \mathrm{C})$. Under such conditions, diethyl terephthalate was only obtained when using $\mathrm{Pt} / \mathrm{C}$ and $\mathrm{Pd} / \mathrm{C}$ catalysts, with $11.9 \%$ and $33.7 \%$ yields, respectively. Increasing the amount of $\mathrm{Pd} / \mathrm{C}$ boosts the hydrogenation reaction, and thus more diethyl terephthalate is formed. The best ratio in term of yield/Pd used was found when using $5 \mathrm{~mol} \%$ of $\mathrm{Pd} / \mathrm{C}$, effectively yielding $70.5 \mathrm{~mol} \%$ on an MA basis. ${ }^{6}$

\section{Dialkylmuconates}

Dialkyl muconates can be synthesized from MA using the known esterification strategies in organic chemistry, or (as in Fig. 2) via chemical routes starting from ester precursors or with incorporation of the ester group during MA synthesis (e.g. for mucic acid conversion. This resembles strategies for lactates vs. lactic acid, where biological routes make acids, and chemical routes can make esters directly. ${ }^{97,98}$ From acids, commonly, Fisher esterification is used, which is an acid catalyzed reaction between muconic acid and an alcohol resulting in the release of water in order to form the corresponding ester. Even though a straightforward reaction path, often high temperatures and long heat exposure are needed to shift the equilibrium sufficiently to the product side. As an alternative, the acid chloride route can be used. Here, the acid is reacted with thionyl chloride (or oxalyl chloride) to form the activated ester. This allows for the reaction time to be decreased dramatically since the acid chloride will react almost immediately in the presence of an alcohol or amine. ${ }^{99,100}$ As for MA, the dialkylmuconates can be used as starting materials for different value-added products and polymers (terephthalic esters, poly muconic esters, ...). Their valorization also depends on the isomeric form of the ester, where the trans,trans isomer maintains its added value for several applications but not for all. Since esterification reactions are widely known, only those, where the activity of 
MA and muconic esters was compared for the covered transformations, are considered in this review.

\section{Polymerization reactions of MA}

As described above, MA can be transformed into a variety of chemicals which can be used as bio-based monomer in polymerizations. Furthermore, due to the different functionalities available, MA itself can also be used is chain growth and step growth polymerization reactions. Presence of the acid groups allows polycondensation reactions while the double bonds makes the structure also applicable for radical addition. This double functionality is relatively unique, and most other monomers in literature will only be able to be polymerized by step growth or chain growth. This versatility of MA is remarkable by itself.

\section{Condensation polymerization of muconic acid and its derivatives}

As mentioned above, adipic acid is converted on a large scale to nylon 6,6. Using biobased MA as feedstock, adipic acid and thus also nylon, can be produced using a renewable, bio-based feedstock. Nylon-6,6 was thus synthesized by Vardon et al. using condensation polymerization of adipic acid combined with 1,6-hexanediamine (Fig. 15-A) via the classic procedure by spinning a stirring rod to pull up a continues strand of nylon as well as the melt polymerization approach which is used in industry. Both commercial and bio-based adipic acid were used to compare the polymeric properties such as the glass transition temperature $\left(T_{g}\right)$ and melting temperature $\left(T_{m}\right)$. Melt polymerization was carried out by synthesis of salts from adipic acid and the diamine to ensure stoichiometric ratios of both compounds. The salts were obtained via precipitating the salts by pouring an aqueous solution containing both compound in isopropanol and melt polymerization was performed. Hereafter, the nylon was recovered from $\mathrm{m}$-cresol. $T_{m}$ and $T_{g}$ were identical between conventional and biobased nylon with $263^{\circ} \mathrm{C}$ and $51^{\circ} \mathrm{C}$, respectively.

Interestingly, 3-hexenedioic acid which also can be derived from MA via electrocatalysis can be used to obtain unsaturated polyamides as well (Fig. 15-B). ${ }^{68}$ Presence of the unsaturation in the polymer resulted in a significant lower $T_{m}\left(60^{\circ} \mathrm{C}\right)$ compared to their nylon-6,6 synthesized from adipic acid $\left(T_{m}=250^{\circ} \mathrm{C}\right)$. The advantage of the unsaturation is the tunability via postpolymerization opportunities to obtain several different polyamides. ${ }^{68}$

While MA is thus interesting as bio-based intermediate for producing other monomers, its direct use as polymer building block is discussed in the following. Rorrer et al. incorporated ccMA into a polymer backbone to synthesize unsaturated polyesters via condensation polymerization with several succinates (Poly(butylene succinate) (PBS), poly(ethylene succinate) (PES), poly(propylene succinate) (PPS) and poly(hexylene succinate) (PHS)). ${ }^{94}$ As a general procedure, first an excess of diol was reacted with the different carboxylic acids (Succinic acid and ccMA) to obtain oligomers from polycondensation. Hereafter, titanium(IV) butoxide was added as transesterification catalyst to promote the condensation reaction of the monomers and transesterification between chains in order to increase the molecular weight resulting in weight-average molecular weights of $4.0 \times 10^{4} \mathrm{~g} \cdot \mathrm{mol}^{-1}$ up to 1.92 $\times 10^{5} \mathrm{~g} \cdot \mathrm{mol}^{-1}$. (see Fig. 16)..$^{94}$

To be able to map the effect of the MA incorporation, the succinate homopolymers were analyzed first (see Table 5)..$^{94}$ All homopolymers show a $T_{g}$ value lower than $-10{ }^{\circ} \mathrm{C}$ and degradation temperatures above $400{ }^{\circ} \mathrm{C}$. While the $T_{m}$ for PES and PBS are above $100{ }^{\circ} \mathrm{C}\left(105^{\circ} \mathrm{C}\right.$ and $130^{\circ} \mathrm{C}$ respectively), the other homopolymers show $T_{m}$ values around $60{ }^{\circ} \mathrm{C}$. Incorporation of MA was performed by adding initially $10 \mathrm{~mol} \%$ relative to the carboxylic groups, as verified by NMR. However, lower molar ratios of muconic acid were incorporated compared to the initial loading. This can be explained by the lower reactivity of MA compared to the other diacids due to the lower acidity caused by the delocalization of the electrons from the double bond. In addition, ${ }^{1} \mathrm{H}$ NMR showed that no thermal isomerization occurred during the polymerization reaction and thus MA was incorporated in the cis,cis conformation. ${ }^{94}$

Incorporation of ccMA into the polysuccinates resulted in a slightly increase in $T_{g}$ and decrease in $T_{m}$ and thermal stability. In contrast to the other polymers, PBS showed a second $T_{g}$ $\left(42^{\circ} \mathrm{C}\right)$ with $6.4 \mathrm{~mol} \%$ incorporation of muconic acid and was further investigated by varying the amount of ccMA in the polymer structure. Lower incorporation (2.2\%) resulted in a lower $T_{g 1}$ value $\left(-29^{\circ} \mathrm{C}\right)$ and higher $T_{g 2}$ value $\left(45^{\circ} \mathrm{C}\right)$ combined

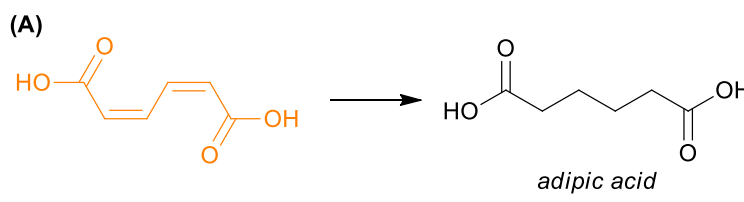

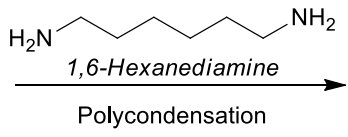

Polycondensation

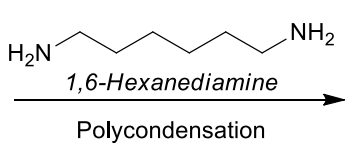

3-hexenedioic acid

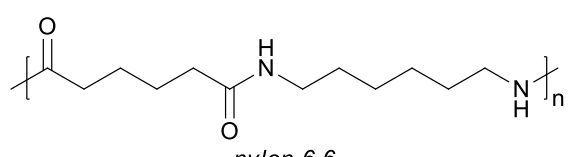

nylon- 6,6

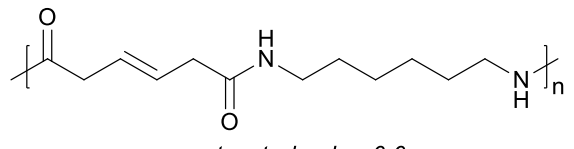

unsaturated nylon-6,6

Fig. 15 - (A) Synthesis of nylon-6,6 from muconic acid using the melt polymerization approach, (B) synthesis of unsaturated nylon-6,6 from muconic acid with 3-hexenedioic acid as intermediate. 


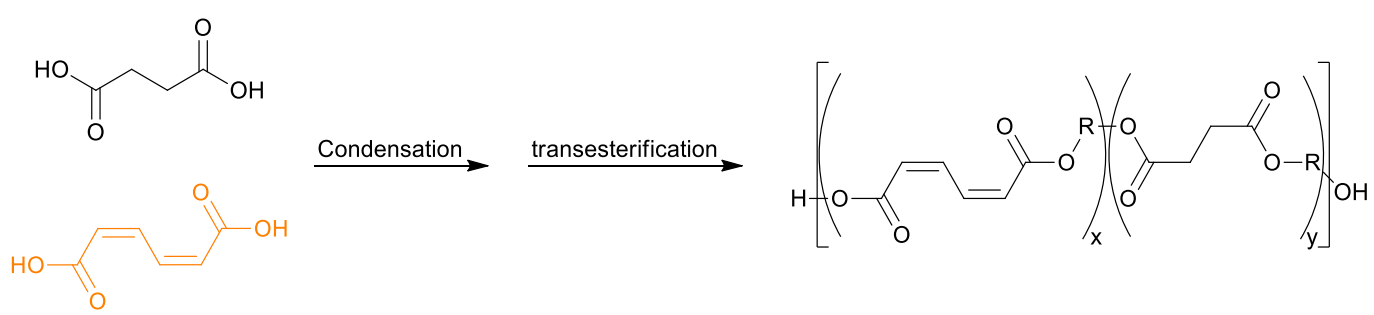

Fig. 16 - General overview of condensation and transesterification reaction of succinic acid and ccMA.

with a slightly higher $T_{m}\left(125^{\circ} \mathrm{C}\right)$. Higher incorporation of MA (12.8\%) resulted in a higher $T_{g 1}$ values $\left(-13^{\circ} \mathrm{C}\right)$ and lower $T_{g 2}$ value $\left(39^{\circ} \mathrm{C}\right)$ combined with a decreased $T_{m}\left(105{ }^{\circ} \mathrm{C}\right) .94$ Increasing $T_{g 1}$ by increasing muconic units is explained by the inhibition of the bond rotation caused by the alkene bond leading to a retardation of the segmental motion. Decrease in $T_{m}$ can on the other hand, can be explained by the formation of less perfect crystals due to the increase of muconic units which disrupt the packing in the polymer crystals. ${ }^{94}$ While poly(ethylene succinate-co-muconate) (PESM), poly(propylene succinate-co-muconate) (PPSM) and poly(hexylene succinateco-muconate) (PHSM) show only one $T_{g}$ value, it is assumed that random copolymers are formed. However, poly(butylene succinate-co-muconate) showed a second $T_{g}$. From the presence of this second $T_{g}$ combined with SEC and TGA analysis, which showed only the presence of one polymer structure, a more block-like structure is assumed. It is speculated that the second $T_{g}$ arises because the MA groups react at a later stage resulting in a polymer with the muconic acid units located preferably at the end of the chain. Furthermore, also cis,cisdimethyl muconate was synthesized and incorporated into the polymer backbone of PBS. While the ester is more soluble in the diol and has a lower melting point, an initial loading of $12.5 \%$ was used and resulted in stoichiometric incorporation of $12.4 \%$. Thermal analysis of the polymer showed a $T_{m}$ of $115^{\circ} \mathrm{C}$ and $T_{g}$ of $-15^{\circ} \mathrm{C}$. No second $T_{g}$ value was observed using the ester. ${ }^{94}$ The advantage of the resulting unsaturations in those polyesters is the tunability in post-polymerization applications. As illustration, PBS copolymers synthesized from both MA as well as DMM as comonomers were crosslinked with styrene using AIBN as initiator resulting in a polyester resin. Some differences between resins from the acid copolymer and the ester copolymer were investigated. Due to the more block-like copolymer structure of the MA copolymer PBSM, the modulus of the resin tends to decrease with increasing molecular weight of the precursor copolymer which allows more tunability than using the random copolymer structure from the muconic ester copolymers. Fiber glass composites made by crosslinking were found to be suitable with a $T_{g}$ of $90{ }^{\circ} \mathrm{C}$ and lack of $T_{m}$ which allows them to be used up to decomposition temperature. ${ }^{94} \mathrm{It}$ can be concluded that muconic acid is a suitable monomer to obtain several interesting bio-based polyesters.

\section{Radical polymerization}

\section{Thermal free radical polymerization}

Radical polymerization of MA and diethyl muconate (DEM) were investigated for the first time by Bando in 1977.101 Muconic acid is poorly soluble in organic solvents but shows limited solubility in DMSO. Therefore, MA $(0.5 \mathrm{~g})$ was polymerized using AIBN as initiator $(25 \mathrm{mg})$ in DMSO $(2 \mathrm{~mL})$ as solvent at 50, 75 and $100^{\circ} \mathrm{C}$ with reaction times from 50 up to 140 hours. Radical addition was investigated via infrared spectroscopy indicating 1,4-radical addition of MA (Fig. 17). In addition, also copolymerization with styrene and acrylonitrile were investigated. ${ }^{101}$ Dialkyl muconates are generally more easy to handle in radical polymerizations due to their better solubility and to the absence of interference from polyelectrolyte effects. Hence, MA was esterified into DEM and consecutively polymerized via anionic polymerization (using nbutyllithium as catalyst), while cationic polymerization was also tested but didn't result in any polymers using boron trifluoride etherate as catalyst. Radical polymerization of DEM ( $4 \mathrm{mmol}$ ) was also performed with AIBN $(0.04 \mathrm{mmol})$ as initiator in benzene at $50^{\circ} \mathrm{C}$ with $24 \mathrm{~h}$ reaction time resulting in muconate oligomers which were soluble in methanol. Here, the radical addition mechanism was investigated, with the same

Table 5 - Summary of thermal properties of succinate homopolymers compared by succinate-co-muconate polymers. ${ }^{94}$

\begin{tabular}{|c|c|c|c|c|c|c|c|c|c|c|}
\hline Homopolymer & $\begin{array}{c}T_{m} \\
\left({ }^{\circ} \mathrm{C}\right)\end{array}$ & $\begin{array}{c}T_{g} \\
\left({ }^{\circ} \mathrm{C}\right)\end{array}$ & $\begin{array}{c}M_{\mathrm{w}} \\
\left(\mathrm{g} \cdot \mathrm{mol}^{-1}\right)\end{array}$ & $\bigoplus$ & $\begin{array}{c}\text { MA incorporation } \\
(\text { mol \%) }\end{array}$ & $\begin{array}{c}T_{m} \\
\left({ }^{\circ} \mathrm{C}\right)\end{array}$ & $\begin{array}{l}T_{g 1} \\
\left({ }^{\circ} \mathrm{C}\right)\end{array}$ & $\begin{array}{l}T_{g 2} \\
\left({ }^{\circ} \mathrm{C}\right)\end{array}$ & $\begin{array}{c}M_{\mathrm{w}} \\
\left(\mathrm{g} \cdot \mathrm{mol}^{-1}\right)\end{array}$ & $\theta$ \\
\hline Poly(ethyl succinate) & 105 & -13 & $4.7 \times 10^{4}$ & 1.9 & 4.6 & 103 & -9 & & $4.0 \times 10^{4}$ & 1.9 \\
\hline Poly(propyl succinate & 48 & -34 & $6.1 \times 10^{4}$ & 1.9 & 6.4 & 46 & -31 & & $5.7 \times 10^{4}$ & 1.9 \\
\hline \multirow[t]{4}{*}{ Poly(butyl succinate) } & 130 & -31 & $1.95 \times 10^{5}$ & 2 & / & 129 & -30 & & $1.92 \times 10^{5}$ & 2 \\
\hline & & & & & 2.2 & 125 & -29 & 45 & $1.21 \times 10^{5}$ & 2 \\
\hline & & & & & 6.4 & 123 & -18 & 42 & $1.03 \times 10^{5}$ & 1.9 \\
\hline & & & & & 12.8 & 105 & -13 & 39 & $9.7 \times 10^{4}$ & 1.9 \\
\hline Poly(hexyl succinate) & 58 & -40 & $8.7 \times 10^{4}$ & 2 & 5.6 & 46 & -31 & & $7.3 \times 10^{4}$ & 1.9 \\
\hline
\end{tabular}


Table 6 - Summary of bulk polymerization results of different muconates using DTBPO $(0.07 \mathrm{mmol})$ as initiator. ${ }^{99}$

\begin{tabular}{lccc}
\hline Muconate & $\begin{array}{c}\text { Reaction } \\
\text { time }(\mathrm{h})\end{array}$ & Yield (\%) & $\begin{array}{c}M_{\mathrm{n}} \\
\left(\mathrm{g} \cdot \mathrm{mol}^{-1}\right)\end{array}$ \\
\hline Cis,cis-methyl & 4 & 57.6 & $16.4 \times 10^{4}$ \\
\hline Cis,cis-ethyl & 4 & 25.2 & $30.3 \times 10^{4}$ \\
\hline Cis,cis-butyl & 4 & 44.6 & $13.8 \times 10^{4}$ \\
\hline Cis,cis-cyclohexyl & 3 & 78.9 & $40.9 \times 10^{4}$ \\
\hline Trans,trans-ethyl & 4 & 60.4 & $10.7 \times 10^{4}$ \\
\hline Trans,trans-isopropyl & 4 & 53.0 & $12.8 \times 10^{4}$ \\
\hline Cis,trans-ethyl & 4 & 44.1 & $13.9 \times 10^{4}$ \\
\hline
\end{tabular}

conclusion of 1,4 radical addition occurring. Given the limitations of that time, no molecular weight values were reported. ${ }^{101}$

Hereafter, Matsumoto performed a more in-depth investigation of free radical polymerization of several alkyl muconates in bulk and partially from the melt. ${ }^{99}$ In addition, different isomers (cis,cis, trans,trans and cis,trans-muconates) were investigated. First the 3 different isomers of several muconates were polymerized in bulk using di-tert-butyl peroxide (DTBPO) as initiator $(0.07 \mathrm{mmol})$ at $120^{\circ} \mathrm{C}$ for $3-4 \mathrm{~h}$ reaction time (results are summarized in Table 6$)^{99}$ to obtain high molecular weight polymers with number-average molecular weights from $10.7 \times 10^{4} \mathrm{~g} \cdot \mathrm{mol}^{-1}$ up to $40.9 \times 10^{4} \mathrm{~g} \cdot \mathrm{mol}$ 1 . The comparison of the conversions of the different isomeric forms of diethyl muconate (cis,cis-, cis,trans- and trans, transisomers) seem to show more pronounced polymerization when using the trans,trans form ( $25 \%$ isolated yield for cis,cis, $44 \%$ for cis, trans and $60 \%$ for trans, trans after the same reaction time). Although this yield is after precipitation, the difference is potentially due to higher trans, trans activity derived from its special geometry with more accessibility to the double bonds. We should mention that this conclusion needs to be taken with some caution and need some confirmation. All isomers yielded high molecular weight polymers. The most bulky monomer (cis,cis-cyclohexyl muconate) showed the highest molecular weight $\left(40.9 \times 10^{4} \mathrm{~g} \cdot \mathrm{mol}^{-1}\right)$ and monomer conversion (78.9\%). This can be explained by the increased viscosity of the polymerization mixture combined with lowering of termination rate coefficients by the increased bulkiness and decreased chain mobility of the ester side chain. ${ }^{99}$ While the bulkiness of the ester chain can influence the molecular weight and yield, it can be concluded that the reactivity between the isomers do not differ significantly because they all show high conversion and molecular weight values. The bulk polymerization of cis,cisdibutyl muconate ( $4 \mathrm{mmol}$ ) was further investigated using again DTBPO $(0.04 \mathrm{mmol})$ at $120^{\circ} \mathrm{C}$ with increasing reaction time (1-

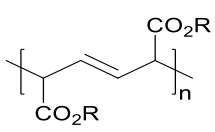

Fig. 17 - 1,4 radical addition product from polymerizing muconic acid $(\mathrm{R}=\mathrm{H})$ or diethyl muconate $\left(\mathrm{R}=\mathrm{CH}_{2} \mathrm{CH}_{3}\right)$.

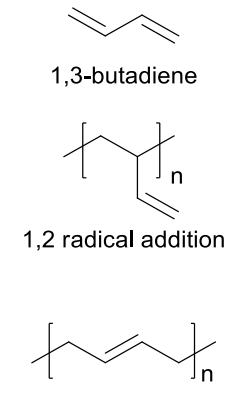

1,4-trans radical addition

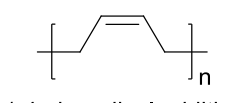

1,4 -cis radical addition

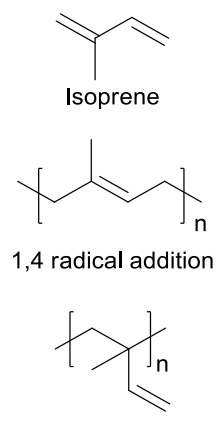

1,2 radical addition

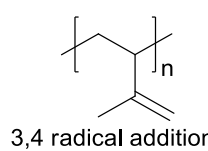

Fig. 18 - Summary of different radical addition products of butadiene and isoprene.

$12 \mathrm{~h}$ ) resulting in polymers of $1 \times 10^{5} \mathrm{~g} \cdot \mathrm{mol}^{-1}$. The yield increased from 15.2 to $82.4 \%$ by increasing the reaction time from 1 to $12 \mathrm{~h}$ as well as the dispersity ( 1.079 after $1 \mathrm{~h}$ to 4.03 after $6 \mathrm{~h}$ ). However, insoluble polymers were obtained after $8 \mathrm{~h}$ reaction time. Therefore, also the initiator 2,2'-azobis(2,4,4trimethylpentane) (ATMP) was tested using the same reaction conditions resulting in soluble polymer of $8.31 \times 10^{4} \mathrm{~g} \cdot \mathrm{mol}^{-1}$ ( $84.3 \%$ yield) with a dispersity of 1.53 . The difference between the azo- and peroxide initiator can be explained by the fact that the peroxide initiator possibly causes hydrogen abstraction of the allylic hydrogens of the polymer backbone resulting in partial crosslinking of the chains. ${ }^{99}$ Besides bulk polymerization, also polymerization in the presence of solvent $(1 \mathrm{~mL})$ was performed at long reaction times with ttDEM $(8 \mathrm{mmol}$ in $p$ xylene, $25 \mathrm{~h}, 89.5 \%$ yield and dimethylformamide (DMF, $17 \mathrm{~h}$, $78.7 \%$ yield) as solvent) and trans,trans diethyl muconate (8 $\mathrm{mmol}$ in DMF, 20h, 77.3 \% yield.) using DTBPO (0.16 mmol) at $120^{\circ} \mathrm{C}$ resulting in significantly lower molecular weights (from $0.71 \times 10^{4}$ up to $\left.1.54 \times 10^{4} \mathrm{~g} \cdot \mathrm{mol}^{-1}\right) .{ }^{99}$

As already known for other dienes such as butadiene or isoprene (Fig. 18), also the muconates can undergo 1,4-trans, 1,4-cis as well as 1,2 radical addition (Fig. 20) in radical polymerizations. ${ }^{99}$ Butadiene typically yields about $28 \% 1,4$-cis, $51 \%$ 1,4-trans and $21 \%$ of the 1,2 addition polymer in free radical polymerization at $100{ }^{\circ} \mathrm{C}$. The amount of 1,4 -cis product can be increased $(43 \%)$ resulting in a decrease of the 1,4-trans product (39\%) by increasing the reaction temperature to $233^{\circ} \mathrm{C}$. However, formation of 1,2 radical addition products shows no significant change upon heating above $200{ }^{\circ} \mathrm{C}$. In addition, also polyisoprene shows the formation of similar polymerization adducts. As comparison, at $100{ }^{\circ} \mathrm{C} 23 \%$ 1,4-cis, 66\% 1,4-trans, $5 \% 1,2$ and $6 \% 3,4$ addition polymer is reported in literature. ${ }^{102}$ While the ratios of the different adducts in polybutadiene were temperature dependent, isoprene polymerization shows less change in adduct formation upon increasing the temperature to $203{ }^{\circ} \mathrm{C}$ (19 \% 1,4-cis, 69\% 1,4-trans, 3\% 1,2 and 9\% 3,4 radical addition product). ${ }^{100,102-104}$ 
The presence of the different polymuconate adducts were investigated by quantitative ${ }^{13} \mathrm{C}$ NMR showing the presence of only $2-4 \%$ of the 1,2 radical addition product relative to the 1,4 polymers. Results show that 1,2 addition is rather limited and not significantly changed by increasing the temperature (from $60-150^{\circ} \mathrm{C}$ ) or varying the isomer form of the monomer. Since the electron withdrawing ester group can stabilize the radical in 1,4 radical addition in muconates, it has an advantage in stability compared to the 1,2 radical addition resulting in a decrease of 1,2-addition compared to butadiene or isoprene. To this extend, the main product is thus the 1,4 polymer. However, also isomerization of the 1,4 addition occurs during polymerization resulting in a mixture of 1,4 cis and 1,4 trans polymers. While the 1,4 trans radical addition is favored, also up to $13 \% 1,4$, cis polymers are formed and their formation increases with increasing the temperature. ${ }^{99}$

Recently, Quintens et al. reinvestigated the free radical polymerization of trans,trans-muconic esters aiming to develop a homogenous production mode for high molecular weight polymuconates as polyacrylate mimics. ${ }^{100}$ DEM is used to optimize the polymerization reaction in solution by varying several parameters as temperature, initiator, reaction time, monomer/initiator concentrations and solvent. Using optimized conditions, poly(diethyl muconate) (PDEM) with a molecular weight of $1.23 \times 10^{5} \mathrm{~g} \cdot \mathrm{mol}^{-1}$ was obtained in solution. Due to lowered reactivity of the monomer, high temperatures $\left(120^{\circ} \mathrm{C}\right)$ were required to obtain reasonable conversions (78\%) using a monomer concentration of $2 \mathrm{~mol} \cdot \mathrm{L}^{-1}$ with di-tert-butyl peroxide (DTBPO, $0.5 \times 10^{-3} \mathrm{~mol} \cdot \mathrm{L}^{-1}$ ) as initiator in anisole with a reaction time of 48 hours. Polymer analysis with ${ }^{1} \mathrm{H}$ and ${ }^{13} \mathrm{C} N M R$ confirmed the formation of $2 \% 1,2$ - and $11 \% 1,4$-cis radical addition product, relative to the desired 1,4-trans structure as already observed in the research of Matsumoto. While the polymer structure can easily be varied by changing the ester side chain, also dibutyl muconate (DBM) and di-2-ethylhexyl muconate (DEHM) were synthesized and polymerized. While the increase of the length of the ester chain in poly(di-butyl muconate) (PDBM) didn't show a significant effect on the obtainable molecular weight $\left(1.17 \times 10^{5} \mathrm{~g} \cdot \mathrm{mol}^{-1}\right)$, the more branched ester chain in poly(di-2-ethylhexyl muconate (PDEHM) resulted in a molecular weight of $3.10 \times 10^{5} \mathrm{~g} \cdot \mathrm{mol}^{-1}$ after 24 hours of reaction time with a conversion of $89 \%$ due to a more pronounced gel-effect. In addition, batch to batch variations were investigated showing the purity of muconic acid/esters is significant in order to obtain high molecular weight polymers above $100000 \mathrm{~g} \cdot \mathrm{mol}^{-1}$. Mark-Houwink parameters were obtained for all three muconates, enabling easier determination of molecular weights of polymers via conventional SEC.

Quintens et al. also showed that polymuconates behave similarly to polyacrylates. Their polymer structure is related and indeed, similar changes in thermal properties are observed when going from one ester to another. Differential scanning calorimetry (DSC) was used in order to determine $T_{g}$ of the different muconates. PDEM showed the highest $T_{g}$ of $7{ }^{\circ} \mathrm{C}$ compared to PDBM with a $T_{g}$ of $-37^{\circ} \mathrm{C}$. The more bulky polymer PDEHM showed the lowest $T_{g}$ of $-60^{\circ} \mathrm{C}$. Literature $T_{g}$ values of

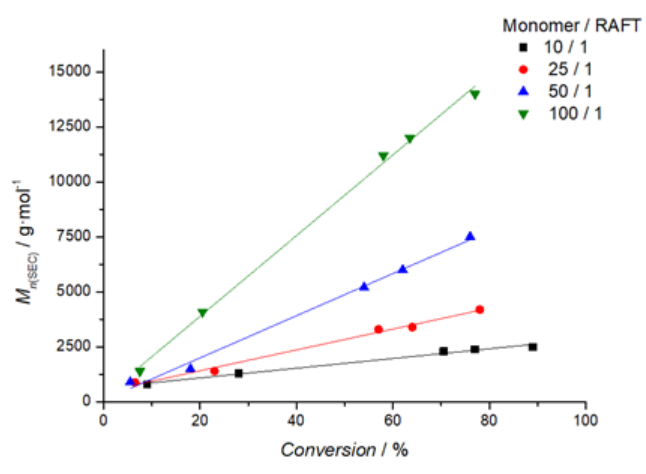

Fig. 19 - Best linear fit of the data points of the number-average molecular weight $(\mathrm{Mn})$ evolution in the RAFT polymerization of diethyl muconate showing different [monomer]/[RAFT] ratios. Reproduced from ref. 100 with permission from RSC, copyright 2019.

their polyacrylate counterparts with the same side chain are $24,-54$ and $-64{ }^{\circ} \mathrm{C}$ respectively showing that polymuconates can in principle be used as a replacement for commercial polyacrylates. ${ }^{100}$

\section{Topochemical polymerization of muconic esters in the crystalline} state

A different approach to polymerize muconates is via photopolymerization in the crystalline state, which was investigated also by Matsumoto and coworkers. Such topochemical route is not without problems.99 Different conditions were tested for CCDEM. Several radiation sources (mercury lamp, sunlight and scattered light) were tested at $0{ }^{\circ} \mathrm{C}$ and room temperature both in air and inert atmosphere. However, ccDMM-, ttDMM, ttDEM and ctDEM did not polymerize at $0{ }^{\circ} \mathrm{C}$ using a mercury lamp in the presence of air. A suspension of CCDEM in water with sunlight as radiation source resulted in polymers at room temperature while there was no polymerization observed in benzene as solvent. Note that monomer crystals were not soluble in water and were soluble in benzene. It was observed that using scattered light, extreme long reaction times were needed (10 days) to obtain $>95 \%$ yield at room temperature in air. Using sunlight (in air atmosphere) or a mercury lamp (combined with a degassed quartz tube) as radiation source, reaction time was decreased significantly to $4 \mathrm{~h}$ at room temperature to obtain already 71.6 and $67.5 \%$ yield, respectively. The resulting polymers from topochemical polymerization of ccDEM were insoluble in

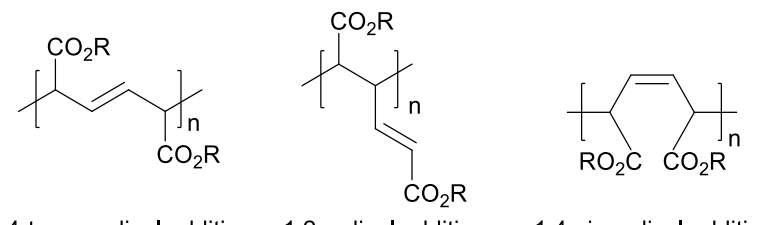

1,4-trans radical addition $\quad 1,2$ radical addition $\quad 1,4$-cis radical addition

Fig. 20 - Overview of different radical addition products using radical polymerization of MA 

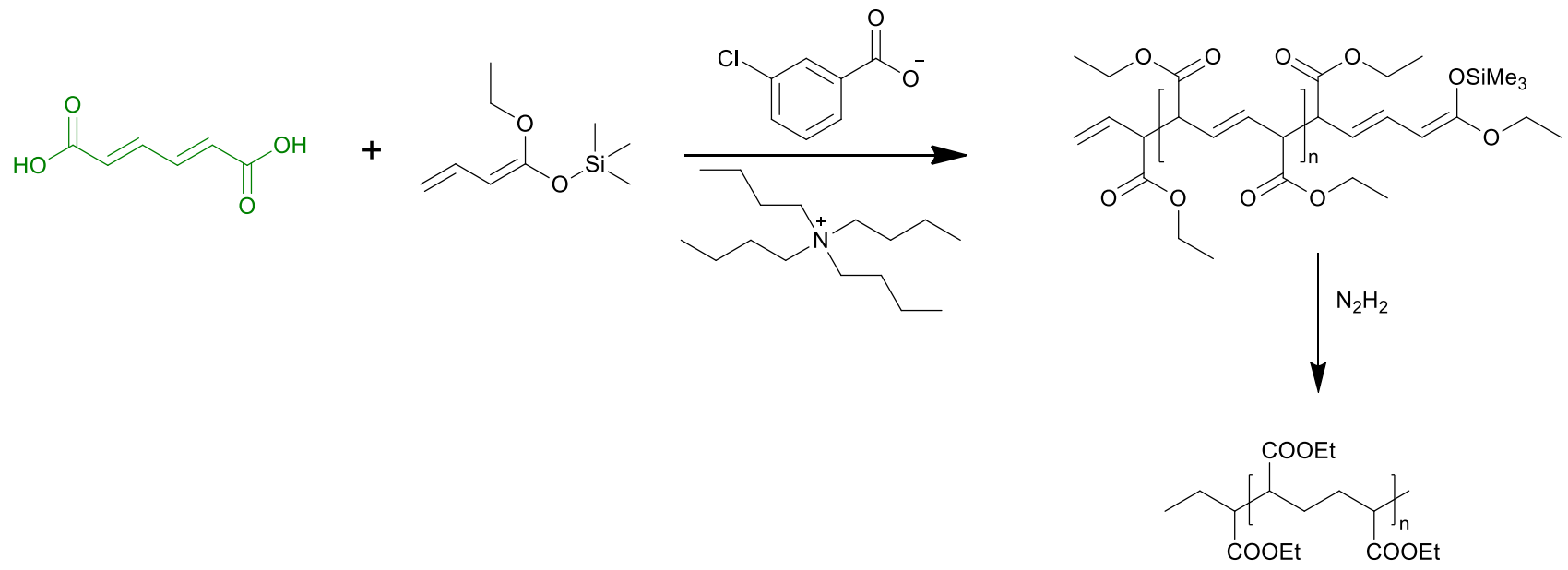

Fig. 21 - Group transfer polymerization (GTP) of diethyl muconate using 1-ethoxy-1 -(trimethylsiloxy)-1,3-butadiene as initiator and tetrabutylammonium m-chlorobenzoate as catalyst followed by hydrogenation with di-imide to determine the diastereoselectivity.

common organic solvents which suggested very high molecular weights were obtained. ${ }^{1} \mathrm{H}$ and ${ }^{13} \mathrm{C}$ NMR analysis showed that in the case of topochemical polymerization, stereoregular polymerization occurred. Compared to the isotropic radical polymerization in bulk which showed also the formation of 1,2and 1,4-cis addition products, topochemical polymerization resulted exclusively in 1,4-trans addition products. ${ }^{99,105,106}$

\section{Controlled polymerization of muconic acid esters}

Reversible deactivation radical polymerization (RDRP) was performed via the reversible addition fragmentation chain transfer (RAFT) polymerization method to exert molecular weight and dispersity control of the polymerization of muconates. ${ }^{100}$ As in solution polymerization, DEM was used as monomer to give a proof of principle. The same optimized FRP conditions as mentioned above were transferred to RAFT polymerization, employing 2-cyano-2-propyl dodecyl trithiocarbonate (CPD-TTC) as control agent. In RAFT, the target molecular weight is determined by the monomer to RAFT agent ratio in solution. Molecular weight evolution of different target molecular weights $\left(1.98 \times 10^{3}, 4.96 \times 10^{3}, 9.91 \times 10^{3}\right.$ and $19.82 \times$ $10^{3} \mathrm{~g} \cdot \mathrm{mol}^{-1}$ ) were investigated by taking samples after $1,5,24$, 30 and 48 hours, resulting in linear increase in molecular weight with monomer conversion. Theoretical and experimental molecular weight matched well, showing a high-quality RAFT control over the polymerization. The best linear fit of the number-average molecular weight evolution is shown in Fig. 19. 100 Dispersities of the polymer remain low as is typical for RAFT, with values between 1.2 and 1.4. These values are typical for diene radical polymerization. ${ }^{104,107}$

\section{Other polymerization types}

In 1985, muconic acid was already used by A. Laschewsky to prepare polymerizable carboxylic acids with hydrocarbon or fluorocarbon chains to develop Langmuir-Blodgett multilayers using UV light. ${ }^{108}$

In 1988 Hertler et al. performed group transfer polymerization (GTP) of DEM using 1-ethoxy-1 -(trimethylsiloxy)-1,3-butadiene as initiator and tetrabutylammonium m-chlorobenzoate as catalyst (Fig. 21). ${ }^{109}$ Polymerization was carried out in THF using two different conditions as shown in Table 7. The reaction temperature increased during polymerization explaining the temperature range which is also indicated in Table 7. Increasing the ratio of monomer to initiator from 10.1 to 28.4 (Table 7 entries 1 and 2) resulted in higher molecular weight polymer with increased dispersity (33 $500 \mathrm{~g} \cdot \mathrm{mol}^{-1}$, dispersity $=2.39$ ) and a $\mathrm{Tg}$ of $15^{\circ} \mathrm{C}$. Note that the determination of molecular weight was still limited at that time. Characterization of the polymer via infrared and ${ }^{1} \mathrm{H}-\mathrm{NMR}$ spectroscopy showed that the polymer is formed by 1,4-polymerization and predominantly in the trans configuration. ${ }^{13} \mathrm{C}-\mathrm{NMR}$ confirmed that there were 3 times as many trans units as cis units present in the polymer backbone. Furthermore, to investigate possible diastereo-selective aspects, Hertler et al. performed hydrogenation using di-imide in order to remove structural inhomogeneities (Fig. 21). ${ }^{109}$

Table 7 - Group transfer polymerization (GTP) conditions of diethyl muconate.

\begin{tabular}{ccccccccc}
\hline Entry & $\begin{array}{c}\text { Monomer } \\
(\mathrm{mmol})\end{array}$ & $\begin{array}{c}\text { Initiator } \\
(\mathrm{mmol})\end{array}$ & $\begin{array}{c}\text { Catalyst } \\
(\mu \mathrm{mol})\end{array}$ & $\mathrm{T}\left({ }^{\circ} \mathrm{C}\right)$ & $\begin{array}{c}\mathrm{M}_{\mathrm{n}} \\
\left(\mathrm{g} \cdot \mathrm{mol}^{-1}\right)\end{array}$ & $\begin{array}{c}\mathrm{M}_{w} \\
\left(\mathrm{~g} \cdot \mathrm{mol}^{-1}\right)\end{array}$ & $\oplus$ & $\begin{array}{c}T_{g} \\
\left({ }^{\circ} \mathrm{C}\right)\end{array}$ \\
\hline 1 & 10.1 & 1.0 & 10 & $28-39{ }^{\circ} \mathrm{C}$ & 1850 & 3330 & 1.80 & $/$ \\
\hline 2 & 35.3 & 1.25 & 10 & $25-35{ }^{\circ} \mathrm{C}$ & 14000 & 33500 & 2.39 & 15 \\
\hline
\end{tabular}


Characterization via ${ }^{13} \mathrm{C}-\mathrm{NMR}$ showed a meso:racemic ratio of 2:1 in poly(diethyl muconate).

\section{Conclusions, insights and outlook}

\section{General conclusion}

The interest in the (biobased) production of muconic acid (MA) is estimated to grow in coming years, due to their potential as starting materials for the synthesis of value-added derivates and as bulk chemicals used in polymer reactions to produce muconic homo- and copolymers. Although MA is a commercial product with a small market already, there is few accessible information on which processes (and uses) dominate commercially. Unique to this potential platform chemical are its isomeric forms. cis, cis MA (ccMA) and cis,trans MA (ctMA) present similar properties with a remarkably higher solubility for ctMA, while the thermodynamically more stable trans, trans MA (ttMA) has a renowned low solubility in common solvents. To meet the needs in MA, biotechnological pathways producing mainly ccMA (and muconate salts), from renewable and lowcost biomass derivatives, as well as petroleum-based feedstock seem to be the most suitable (Fig. 22), although some interesting catalytic deoxydehydration routes have been reported. Biotechnologically, the maximum titer of $85 \mathrm{~g} / \mathrm{L}$ of ccMA $^{2-}$ was obtained with a C. glutamicum strain, on catechol. After its biological production in the cis,cis configuration, purification of ccMA can be performed directly or after an insitu isomerization to ctMA, that allows easier purification due to its better solubility in organic solvents. A second isomerization can then be performed to obtain the more valuable ttMA isomer, specifically desired for some applications. The first isomerization of ccMA to ctMA is spontaneous for $\mathrm{pH}$ values lower than 4 (e.g. total conversion in 3 days in water at room temperature). At neutral $\mathrm{pH}$, isomerization into the cis,trans isomer in water is no longer spontaneous. The ctMA isomerization to ttMA requires harsh chemical activation. Processes using hydrogenation catalysts $(\mathrm{Pd} / \mathrm{C})$ or $\mathrm{I}_{2}$ under UV irradiation have shown the best performances (yield $>80 \%$ ). However, limitations here reside in the feed solutions being rather dilute (e.g. a max of $10 \mathrm{wt} . \%$ of muconic acid in the case of the iodine system), the use of undesired iodine or the high cost of noble metals. This stimulates the search for new economic and more sustainable isomerization processes. In this sense, the thermal heating of CCMA and ctMA in DMSO in presence of a precise amount of water yielded $73 \%$ of ttMA without iodine or metals. Nevertheless, this process does not work well at medium to high MA concentrations (e.g. for 25 wt.\%), where ttMA is no longer observed in the products and only muconic mono- and di-lactones formed. Lactone formation is something to avoid aiming at isomerization. Soluble Lewis acids were also found to favor ttMA production $(40 \%$ yield instead of $0 \%$ in their absence) due to their coordination with $\mathrm{C}=\mathrm{C}$ bonds, facilitating rotation around the $\mathrm{C} 2-\mathrm{C} 3$ or $\mathrm{C} 4-\mathrm{C} 5$ axis, leading to formation of the thermodynamically preferred trans,trans isomer. Another way to allow isomerization to ttMA, as opposed to intramolecular lactonization, relies on complexing the carboxylate functionalities (e.g. with $\mathrm{La}^{3+}$ salts). This method has shown a decent selectivity toward ttMA (55\%), but on top of being limited to a specific $\mathrm{pH}$, the difficult recovery of ttMA, as well as the though regeneration of $\mathrm{La}^{3+}$ salts, add constraints to the use of this method. Finally, an innovative electrochemical pathway has been shown to produce ttMA from cc/ct-MA, however, obtained yields did not exceed $10 \%$. It is clear that a large-scale (iodine-free) viable isomerization process is still lacking.

The three isomers of MA can be used as starting materials for synthesizing value-added derivates, such as adipic acid, $\varepsilon$ caprolactam and terephthalic acid and also less-common chemicals such as muconolactones, hexenedioic acids, and caprolactone. ${ }^{5,8}$ The catalytic hydrogenation of ccMA and ttMA, using supported noble metals ( $\mathrm{Pt} / \mathrm{C}, \mathrm{Pd} / \mathrm{C}, \mathrm{Re} / \mathrm{TiO}_{2} \ldots$ ), quantitatively yields adipic acid. Experimental and theoretical comparisons of the behavior of ccMA and ttMA isomers, have shown that total hydrogenation of ccMA appears to be more spontaneous than for ttMA. When working with muconic esters such as DMM, the transformation into adipic esters is less quantitative and easy.

MA can also be prone to intramolecular cyclisation to form muconolactone and muconic dilactone. Lactonization preferentially occurs in protic solvents at low $\mathrm{pH}$. It was found that only ccMA and ctMA isomers can perform lactonization, while the spatial conformation of ttMA prevents the intramolecular attack of the carboxylic on the interior C4 adjacent carbon. A more interesting product that can be derived from MA cyclization, combined with other reactions, is $\varepsilon$ caprolactam. The three isomers were found to be active in this transformation, however, a lower selectivity was obtained with ttMA. After a thermal treatment under $\mathrm{NH}_{3}$ and $\mathrm{H}_{2}$, in presence of Pd catalyst, muconic amides and adipamide were formed from MA. The cyclization reactions of these amides, under the same conditions, lead to the seven-membered ring $\varepsilon$ caprolactam, the main nylon 6 precursor.

The main importance given to the ttMA isomer is due to its ability to perform Diels-Alder reactions, in the role of diene, and if followed by dehydrogenation, can lead to terephthalic acid (41\%), the main building block of PET plastics. The steric natures of both ccMA and ctMA isomers prohibit the Diels-Alder reaction. The relative low yield of the reaction so far could be due to the initial low solubility of ttMA in the used solvents. To counter solubility issues, esterifying ttMA is a key solution, as the higher solubility of esters promotes the Diels-Alder reaction, to give almost quantitative yields of terephthalic precursors (and the actual ester after dehydrogenation).

Muconic acid and its esters are also readily polymerized via either polycondensation or chain growth polymerization. This ability to switch (and possibly to combine) these two types of polymerization opens avenues to complex polymer design. The polycondensation route can be used to produce nylon-type of polymers, that feature unsaturation in the backbone, allowing for crosslinking and backbone modification in post- 
polymerization procedures. Such condensates can thus serve as resins for a variety of purposes. The chain growth polymerization can be conveniently performed via radical polymerization. Despite some earlier limitations believed to exist for these polymerizations, more recent research shows that dialkyl muconates behave in line with other dienes and show even slightly higher reactivity. Polymerizations behave close to the ideal, and also controlled polymerizations via RDRP methods can be carried out, making biobased muconates a versatile building block in polymerizations. First studies into properties of polymuconates show that these polymers may be able to serve as substitutes for polyacrylates, and hence as sustainable alternative for an oil-based commodity product. Future research will need to focus further on the exploitation of post-polymerization potential and on mechanical properties of this interesting class of polymers. Finally, despite the potential of $M A$, its relatively high production price via the known production pathways is still a hurdle for its viable production at large scale. Significant work still needs to be done in order to achieve more attractive production costs.

\section{Insights}

In no particular order, some insights into the purification, isomerization, transformation and polymerization of MA can be mentioned:

- Concerning its biological production and purification, due to the low solubility of ccMA in many solvents, its conversion to ctMA (more soluble) was found to facilitate the purification step. However, a pre-esterification can be another key step to increase the purification efficiency due to high solubility of muconic esters in organic solvents.

- The first isomerization of ccMA into ctMA was shown to be spontaneous and quantitative. It can occur at low temperature, at $\mathrm{pH}$ values lower than 6 . More care should be given to the identification of the produced isomer(s) during the biotechnological pathways using acidic media. Moreover, the spontaneous isomerization adds inherent difficulties for the identification (acids and salts) of the solubility values of the cis,cis isomer, thus the potential presence of ct must always be taken into consideration.

- Using DMSO as solvent has selectively yielded ttMA without other reagents. The mechanism and the role of DMSO is not understood well, but could offer an interesting route for catalyst or active site design.

- A soluble Lewis acid $\left(\mathrm{AlBr}_{3}\right)$ was found to coordinate with muconic acid double bonds enabling the formation of

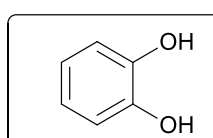

Catechol

(C. glutamicum)<smiles>O=C([O-])c1ccccc1</smiles>

Benzoate (Pseudomonas)

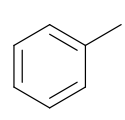

Toluene (Arthrobacter)

$\mathrm{OH}$<smiles>OC[C@H]1O[C@H](O)[C@@H](O)[C@H](O)[C@@H]1O</smiles>

Glucose

(E. coli)

\section{Polymers}

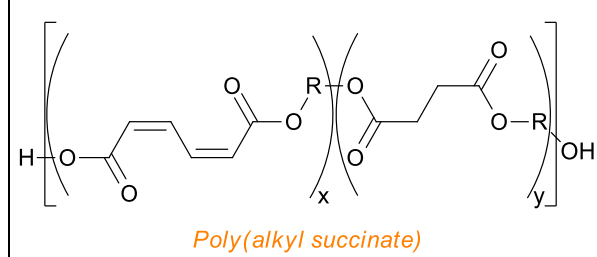

Poly(alkyl succinate)<smiles>[R]OC(=O)C(C=CC(C)(C)C)C([R])[R]</smiles>

1,4-polymuconic acid (ester)

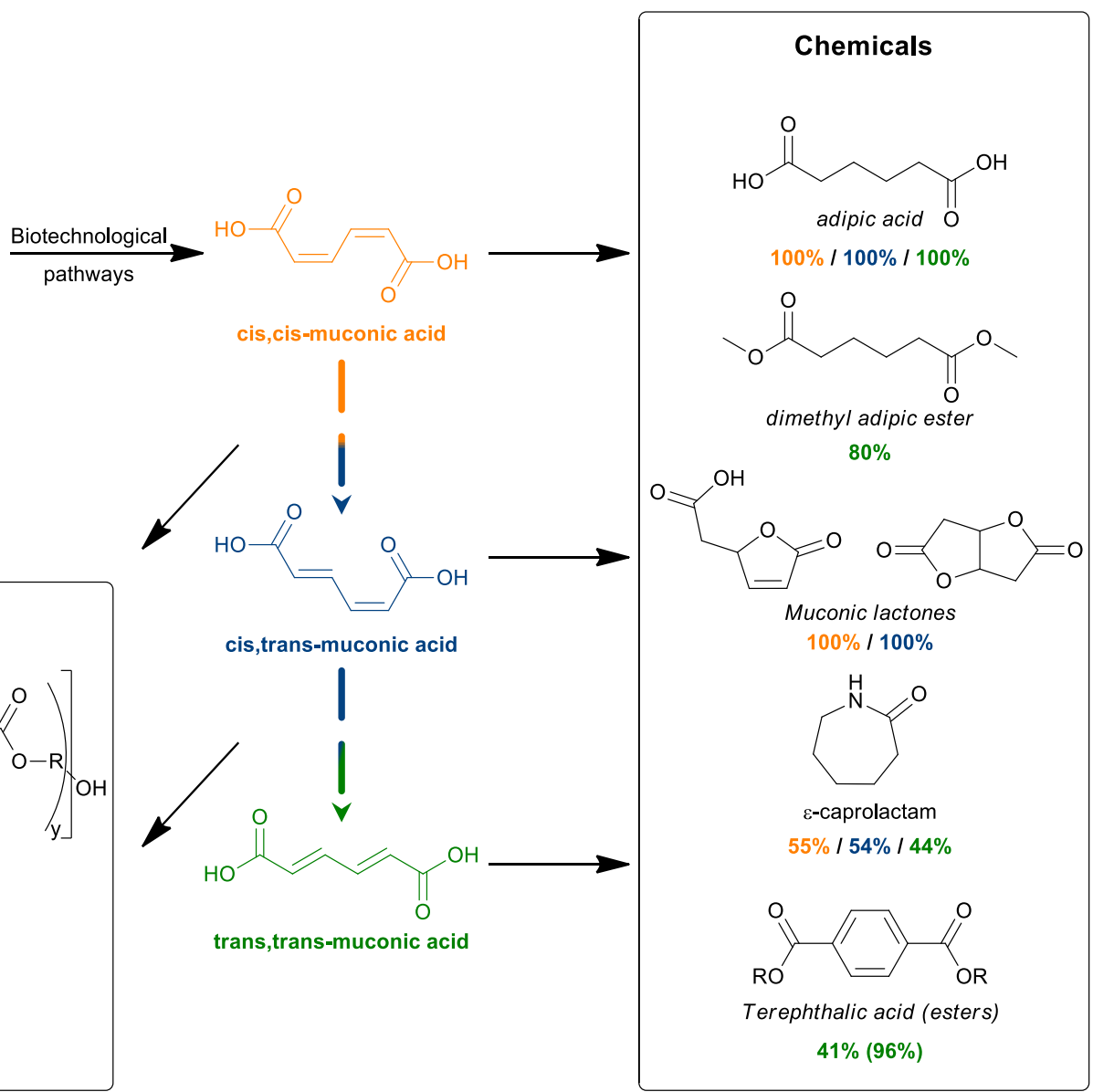

Fig. 22 - Summary of the biotechnological pathways producing the ccMA, and the possible transformation of the three isomers of MA. The yields in color indicate from which isomer they were obtained. ttMA is the only one that can lead to terephtalic acid (or esters), in reverse, it cannot undergo lactonization. 
trans,trans isomer. The search for heterogeneous Lewis acidic sites in or on low cost and recyclable catalyst supports, e.g. zeolites, might provide promising ecological and economical isomerization routes.

- Electrochemical pathways using earth-abundant metals, such as $\mathrm{Fe}$ and $\mathrm{Cu}$, as electrodes have led to the formation of the ttMA in low yields. An investigation of the activity of these as transition metal (Lewis acidic) catalysts in isomerization reaction could be interesting.

- To implement an industrial scale production of ttMA, new heterogeneous catalyzed processes must be developed. An ideal sustainable route would fulfil as many of the 'green chemistry' principles as possible. In ttMA context, especially no sacrificial reagents, highly concentrated or solvent-free, renewable feedstocks, high (catalyst) selectivity, high atom economy, and waste prevention are important considerations in process design, even at the lab scale. ${ }^{110}$

- Dialkyl muconates can be polymerized in facile manner, yielding polymers with high molecular weight and thermal properties comparable to polyacrylates. A study of the properties and applications of such polyacrylate lookalikes is due.

- The higher accessibility of double bonds in the trans,transform of MA and dialkyl muconates may allow a better activity in radical polymerization reactions. A dedicated study screening the bulk polymerization rates and intrinsic kinetics of the isomeric forms of different muconates should confirm this.

- Dialkyl muconate as monomer for the radical route follows general trends in radical polymerization, and can be well controlled via RDRP methods, making these monomers available for high-added value materials design and likely suitable for co-monomer mixing.

\section{Outlook}

With its potential as a starting material for the synthesis of value-added derivates and as a bulk chemical used in polymer reactions to produce muconic homo and copolymers, the biotechnological production of MA is expected to intensify in coming years. By developing specific protocols and processes, high titers of ccMA from biobased catechol were obtained ( 85 $\mathrm{g} / \mathrm{L}$ ). However, these titers should still be increased. Purification and isolation steps after the fermentation still present certain limitations in terms of cost and need to deal with the low solubility of MA isomers. In situ isomerization to ctMA may improve the solubility, but the additional cost of using a solvent for isolation is still not countered. The integration of a one-pot process allowing esterification right after the biological production or in situ, could be an interesting avenue, especially since the esters are more soluble and in certain applications of MA, a preferred starting point. Despite its high potential as starting material and the large progress reported in its production pathways, the cost of the production of MA is still high in comparison to the value of some of its targeted final applications (roughly estimated at 3-4 USD/kg for MA in comparison to an estimated 1.0 and $0.8 \mathrm{USD} / \mathrm{kg}$ for adipic and terephthalic acid, respectively). ${ }^{9,111,112}$ It is clear that to truly propel MA to a large-or medium scale platform chemical of the biobased industry, a cost effective and thus technologically efficient production will be needed, supplemented with effective recovery and isomerization processes. In that respect, a holistic approach taking into account production and application, with isomerization as a potential link, including the respective reaction media (solvents), is needed. For example, attempts to isolate ctMA from the broth in solvents where the transformation into adipic acid or $\varepsilon$-caprolactam can be performed, could be worth exploring. Economic attractiveness of the route to adipic acid or $\varepsilon$-caprolactam from the biotechnological produced MA will thus mostly rely on the efficiency and cost of the biotechnological synthesis of MA, and separation/purification operations. Other examples are the terephthalic derivates, where the use of muconic esters has shown better yields and selectivity than the acid feedstock. A sustainable and low-cost isomerization process to ttMA, in the same solvent as needed afterward for Diels-Alder, would offer an potentially attractive solution.

It is clear that MA also has good potential as a monomer on its own, but that relatively little has been explored. Furthering the use of MA and its derivatives in polymerization protocols, in combination with better availability of these building blocks, will allow for the development of new classes of polymers that has the potential to replace (or augment) current commodity materials. An interesting example is radical ( 1,4 addition) derived polymers with a polyacrylate nature, potentially of use as water adsorbents or polyelectrolytes.

It should be clear that MA is an interesting, potentially biobased molecule with platform potential. Its platform potential will depend on the ease to link-up biotech pathways, via innovative purification and isomerization protocols, to the reactions or polymerizations, that lead to the added-value target products (which are plenty). A holistic MA perspective, as presented in this critical review, will be of utmost importance.

\section{Conflicts of interest}

\section{There are no conflicts of interest to declare.}

\section{Acknowledgements}

The authors thank the SPICY (Sugar-based chemicals and Polymers through Innovative Chemocatalysis and engineered Yeast) project of VLAIO Catalisti for funding.

\section{References}

1 N. Z. Xie, H. Liang, R. B. Huang and P. Xu, Biotechnology Advances, 2014, 32, 615-622. 
2 J. M. Carraher, T. Pfennig, R. G. Rao, B. H. Shanks and J. P. Tessonnier, Green Chemistry, 2017, 19, 3042-3050.

3 Research and Market, Global Muconic Acid Market to 2023. Market is Expected to Reach $\$ 110+$ Million, January 2019, https://www.prnewswire.com/newsreleases/global-muconic-acid-market-to-2023market-is-expected-to-reach-110-million300772411.html.

4 Imarc Group, Muconic Acid Market Size, Share, Trends and Forecast 2019-2024, https://www.imarcgroup.com/muconic-acidmarket.

5 J. E. Matthiesen, J. M. Carraher, M. Vasiliu, D. A. Dixon and J. P. Tessonnier, ACS Sustainable Chemistry \& Engineering, 2016, 4, 3575-3585.

6 R. Lu, F. Lu, J. Chen, W. Yu, Q. Huang, J. Zhang and J. Xu, Angew. Chem. Int. Ed., 2016, 55, 249-253.

7 J. L. Milan, M. Mang and C. Ozmeral, US Patent, 2017, US20170335031A1.

8 B. H. Shanks and P. L. Keeling, Green Chem., 2017, 19, 3177-3185.

9 Global Market Insights, Muconic Acid Market Report, Sample Page, 2017.

10 G. Scherer, T. Renner and M. Meger, Journal of Chromatography B: Biomedical Sciences and Applications, 1998, 717, 179-199.

11 T. Ruppert, G. Scherer, A. R. Tricker and F. Adlkofer, International Archives of Occupational and Environmental Health, 1997, 69, 247-251.

12 M. Dusselier, M. Mascal and B. F. Sels, Selective Catalysis for Renewable Feedstocks and Chemicals Springer International Publishing, 2014, 353, 1-40.

13 J. W. Frost, A. Miermont, D. Schweitzer and V. Bui, US Patent, 2013, US8426639B2.

14 R. Beerthuis, G. Rothenberg and N. R. Shiju, Green Chemistry, 2015, 17, 1341-1361.

15 J. A. Elvidge, R. P. Linstead, P. Sims and B. A. Orkin, Journal of the Chemical Society, 1950, 2235-2241.

16 V. Bui, D. MacRae and D. Schweitzer, US Patent, 2014, US8809583.

17 A. J. Pandell, The journal of organic chemistry, 1976, 41, 3992-3996.

18 J. Tsuji and H. Takayanagi, Tetrahedron, 1977, 34, 641-644.

19 T. Polen, M. Spelberg and M. Bott, Journal of Biotechnology, 2013, 167, 75-84.

20 N. S. Kruyer and P. Peralta-Yahya, Current Opinion in Biotechnology, 2017, 45, 136-143.
21 A. Baeyer and H. Rupe, Justus Liebig's Annalen der Chemie, 1890, 256, 1-28.

22 R. Behrend, Berichte der deutschen chemischen Gesellschaft, 1916, 49, 999-1003.

23 S. Ruhemann and F. F. Blackman, J. Chem. Soc., 1890, 57, 370-375.

24 S. Ruhemann, J. Chem. Soc., 1890, 57, 937-944.

25 C. K. Ingold, Journal of the Chemical Society, 1921, 119, 951-970.

26 M. Shiramizu and F. D. Toste, Angew. Chem. Int. Ed., 2013, 52, 12905-12909.

27 S. Qu, Y. Dang, M. Wen and Z.-X. Wang, Chemistry - A European Journal, 2013, 19, 3827-3832.

28 M. Shiramizu and F. D. Toste, Angew. Chem. Int. Ed., 2012, 51, 8082-8086.

29 X. Li, D. Wu, T. Lu, G. Yi, H. Su and Y. Zhang, Angew. Chem., 2014, 126, 4284-4288.

30 P. C. Guha and D. K. Sankaran, Organic Syntheses, 1946, 26, 57-60.

31 E. H. Farmer, Journal of Chemical Society, 123, 2531-2548.

32 J. Böeseken and R. Engelberts, Proc. Acad. Sci. Amesterdam, 1931, 34, 1292.

33 J. Böeseken, Proc. Acad. Sci. Amesterdam, 1932, 35, 750-755.

34 J. Böeseken and C. L. M. Kerkhoven, Recueil des Travaux Chimiques des Pays-Bas, 1932, 51, 964970.

35 J. Böeseken and G. Slooff, Proc. Acad. Sci. Amesterdam, 1929, 32, 1043-1045.

36 C. Grundmann, Berichte der deutschen chemischen Gesellschaft, 1936, 69, 1755-1757.

37 I. Khalil, H. Jabraoui, G. Maurin, S. Lebègue, M. Badawi, K. Thomas and F. Maugé, J. Phys. Chem. C, 2018, 122, 26419-26429.

38 J. Zakzeski, P. C. A. Bruijnincx, A. L. Jongerius and B. M. Weckhuysen, Chemical Reviews, 2010, 110, 3552-3599.

39 W. Schutyser, T. Renders, S. Van den Bosch, S.-F. Koelewijn, G. T. Beckham and B. F. Sels, Chem. Soc. Rev., 2018, 47, 852-908.

40 H. Jabraoui, I. Khalil, S. Lebègue and M. Badawi, Mol. Syst. Des. Eng., 2019, 4, 882-892.

41 P. C. Maxwell, US Patent, 1982, US4355107.

42 P. C. Maxwell, US Patent, 1991, US5026648.

43 A. Kaneko, Y. Ishii and K. Kirimura, Chemistry Letters, 2011, 40, 381-383.

44 B. Thompson, S. Pugh, M. Machas and D. R. Nielsen, ACS Synth. Biol., 2018, 7, 565-575. 
45 Q. Ke, T. Sun, H. Cheng, X. Wei, Y. Guo, S. Zhao, S. Zeng and S. Wang, Ind. Eng. Chem. Res., 2018, 57, 16763-16771.

46 C. S. Harwood and R. E. Parales, Annual Review of Microbiology, 1996, 50, 553-590.

47 I. Khalil, K. Thomas, H. Jabraoui, P. Bazin and F. Maugé, Journal of Hazardous Materials, 2020, 384, 121397.

48 J. Becker, M. Kuhl, M. Kohlstedt, S. Starck and C. Wittmann, Microb Cell Fact, 2018, 17, 115-128.

49 S. Mizuno, N. Yoshikawa, M. Seki, T. Mikawa and Y. Imada, Applied Microbiology and Biotechnology, 1988, 28, 20-25.

50 Y. Liao, R. Zhong, E. Makshina, M. d'Halluin, Y. van Limbergen, D. Verboekend and B. F. Sels, ACS Catal., 2018, 8, 7861-7878.

51 J. Bomon, E. V. D. Broeck, M. Bal, Y. Liao, S. Sergeyev, V. V. Speybroeck, B. F. Sels and B. U. Maes, Angew. Chem., , DOI:10.1002/ange.201913023.

52 M. Kohlstedt, S. Starck, N. Barton, J. Stolzenberger, M. Selzer, K. Mehlmann, R. Schneider, D. Pleissner, J. Rinkel, J. S. Dickschat, J. Venus, J. B.J.H. van Duuren and C. Wittmann, Metabolic Engineering, 2018, 47, 279-293.

53 C. M. Wu, C. C. Wu, C. C. Su, S. N. Lee, Y. A. Lee and J. Y. Wu, Biochemical Engineering Journal, 2006, 29, 35-40.

54 Y. Imada, Y. Nobuji, M. Sumiko and M. Takashi, US Patent, 1989, US4871667.

55 E. Schmidt and H. J. Knackmuss, Applied Microbiology and Biotechnology, 1984, 20, 351355.

56 N. Z. Xie, Q. Y. Wang, Q. X. Zhu, Y. Qin, F. Tao, R. B. Huang and $\mathrm{P}$. $\mathrm{Xu}$, Preparative Biochemistry and Biotechnology, 2014, 44, 342-354.

57 J. W. Chua and J. H. Hsieh, World Journal of Microbiology and Biotechnofogy, 1990, 6, 127-143.

58 J. H. Hsieh and P. C. Maxwell, US Patent, 1985, US4535059.

59 J. H. Hsieh, US Patent, 1984, US4480034.

60 J. H. Hsieh, US Patent, 1990, US4968612.

61 N. Yoshikawa, S. Mizuno, K. Ohta and M. Suzuki, Journal of Biotechnology, 1990, 14, 203-210.

62 W. Niu, K. M. Draths and J. W. Frost, Biotechnology Progress, 2002, 18, 201-211.

63 J. W. Frost and K. M. Draths, US Patent, 1997, US5616496.

64 C. Weber, C. Brückner, S. Weinreb, C. Lehr, C. Essl and E. Boles, Applied and Environmental Microbiology, 2012, 78, 8421-8430.
65 X. Sun, Y. Lin, Q. Huang, Q. Yuan and Y. Yan, Applied and Environmental Microbiology, 2013, 79, 4024-4030.

66 K. M. Draths and J. W. Frost, J. Am. Chem. Soc., 1994, 116, 339-400.

67 K. A. Curran, J. M. Leavitt, A. S. Karim and H. S. Alper, Metabolic Engineering, 2013, 15, 55-66.

68 M. Suastegui, J. E. Matthiesen, J. M. Carraher, N. Hernandez, N. Rodriguez Quiroz, A. Okerlund, E. W. Cochran, Z. Shao and J. P. Tessonnier, Angewandte Chemie International Edition, 2016, 55, 2368-2373.

69 J. M. Leavitt, J. M. Wagner, C. C. Tu, A. Tong, Y. Liu and H. S. Alper, Biotechnology Journal, 2017, 12, 131.

70 D. R. Vardon, N. A. Rorrer, D. Salvachúa, A. E. Settle, C. W. Johnson, M. J. Menart, N. S.

Cleveland, P. N. Ciesielski, K. X. Steirer, J. R. Dorgan and G. T. Beckham, Green Chemistry, 2016, 18, 3397-3413.

71 V. Bui, D. MacRae and D. Schweitzer, US Patent, 2013, US0030215.

72 A. E. Settle, L. Berstis, S. Zhang, N. A. Rorrer, H. Hu, R. M. Richards, G. T. Beckham, M. F. Crowley and D. R. Vardon, ChemSusChem, 2018, 11, 1768-1780.

73 J. W. Frost, A. Miermont, D. Schweitzer and V. Bui, US Patent, 2010, US0314243 A1.

74 J. M. Carraher, J. E. Matthiesen and J. P. Tessonnier, Journal of Molecular Liquids, 2016, 224, 420-422.

75 J. P. Tessonier, J. M. Carraher, T. Pfennig and B. Shanks, US Patent, 2018, US9957218 B2.

76 D. I. Collias, A. M. Harris, V. Nagpal, I. W. Cottrell and M. W. Schultheis, Industrial Biotechnology, 2014, 10, 91-105.

77 J. Vaugeois and J. D. Wuest, J. Am. Chem. Soc., 1998, 120, 13016-13022.

78 L. G. Sillen and A. E. Martell, Chem. Soc., 1971, 298, 400-401.

79 J. M. Carraher, T. Pfennig, R. G. Rao, B. H. Shanks and J. P. Tessonnier, Green Chemistry, 2017, 19, 3042-3050.

80 J. J. Bozell and G. R. Petersen, Green Chem., 2010, 12, 539-554.

81 S. Van de Vyver and Y. Román Leshkov, Catal. Sci. Technol., 2013, 3, 1465-1479.

82 A. Rosengart, S. Capelli, C. Pirola, A. Citterio, L. Prati and $A$. Villa, Chemical engineering transactions, 2017, 57, 1-6.

83 J. M. Thomas, R. Raja, B. F. G. Johnson, T. J. O'Connell, G. Sankar and T. Khimyak, ChemComm, 2003, 34, 1126-1127. 
84 D. R. Vardon, M. A. Franden, C. W. Johnson, E. M. Karp, M. T. Guarnieri, J. G. Linger, M. J. Salm, T. J. Strathmann and G. T. Beckham, Energy \& Environmental Science, 2015, 8, 617-628.

85 X. She, H. M. Brown, X. Zhang, B. K. Ahring and Y. Wang, ChemSusChem, 2011, 4, 1071-1073.

86 S. Capelli, A. Rosengart, A. Villa, A. Citterio, A. Di Michele, C. L. Bianchi, L. Prati and C. Pirola, Applied Catalysis B: Environmental, 2017, 218, 220-229.

87 J. A. Elvidge, R. P. Linstead, B. A. Orkin, P. Sims, H. Baer and D. B. Patrison, Journal of the Chemical Society, 1950, 2228-2234.

88 H. Blatt, Chemical Reviews, 1932, 12, 215-260.

89 L. Coudray, V. Bui and J. W. Frost, US Patent, 2012, US032774.

90 M. Li, Manuscript, 2013, 1-203.

91 P. Raghavendrachar and S. Ramachandran, Ind. Eng. Chem. Res., 1992, 31, 453-462.

92 R. A. F. Tomás, J. C. M. Bordado and J. F. P. Gomes, Chem. Rev., 2013, 113, 7421-7469.

93 M. B. Banella, C. Gioia, M. Vannini, M. Colonna, A. Celli and A. Gandini, ChemSusChem, 2016, 9, 942945.

94 N. A. Rorrer, J. R. Dorgan, D. R. Vardon, C. R. Martinez, Y. Yang and G. T. Beckham, ACS Sustainable Chemistry \& Engineering, 2016, 4, 6867-6876.

95 J. W. Frost, A. Miermont, D. Schweitzer and D. A. Wicks, US Patent, 2013, US8367858B2.

96 F. Rammal, A. C. Gaumont and S. Lakhdar, European Journal of Organic Chemistry, 2020, n/a, 4.

97 M. Dusselier, P. Van Wouwe, A. Dewaele, E. Makshina and B. F. Sels, Energy Environ. Sci., 2013, 6, 1415.

98 M. Dusselier, R. De Clercq, R. Cornelis and B. F. Sels, Catalysis Today, 2017, 279, 339-344.

99 A. Matsumoto, T. Matsumura and S. Aoki, Macromolecules, 1996, 29, 423-432.

100 G. Quintens, J. Vrijsen, P. Adriaensens, D. Vanderzande and T. Junkers, Polymer Chemistry, 2019, 40, 5555-5563.

101 Y. Bando, T. Dodou and Y. Minoura, Journal of Polymer Science: Polymer Chemistry Edition, 1977, 15, 1917-1926.

102 G. Odian, Principles of Polymerization, John Wiley \& Sons, 2004.

103 M. Kerns, S. Henning and M. Rachita, in Encyclopedia of Polymer Science and Technology, American Cancer Society, 2002.

104 G. Moad, Polymer International, 2017, 66, 26-41.
105 T. Odani and A. Matsumoto, Macromolecular Rapid Communications, 2000, 21, 40-44.

106 A. Matsumoto, K. Katayama, T. Odani, K. Oka, K. Tashiro, S. Saragai and S. Nakamoto, Macromolecules, 2000, 33, 7786-7792.

107 V. Jitchum and S. Perrier, Macromolecules, 2007, 40, 1408-1412.

108 A. Laschewsky, H. Ringsdorf and G. Schmidt, Thin Solid Films, 1985, 134, 153-172.

109 W. R. Hertler, T. V. RajanBabu, D. W. Ovenall, G. S. Reddy and D. Y. Sogah, J. Am. Chem. Soc., 1988, 110, 5841-5853.

110 P. T. Anastas, M. M. Kirchhoff and T. C. Williamson, Applied Catalysis A: General, 2001, 221, 3-13.

111 Adipic Acid Price Market Analysis - Echemi, https://www.echemi.com/productsInformation/pd 20150901270-adipic-acid.html.

112 Terephthalic acid Price Market Analysis - Echemi, https://www.echemi.com/productsInformation/pi d_Seven1068-terephthalicacid.html. 


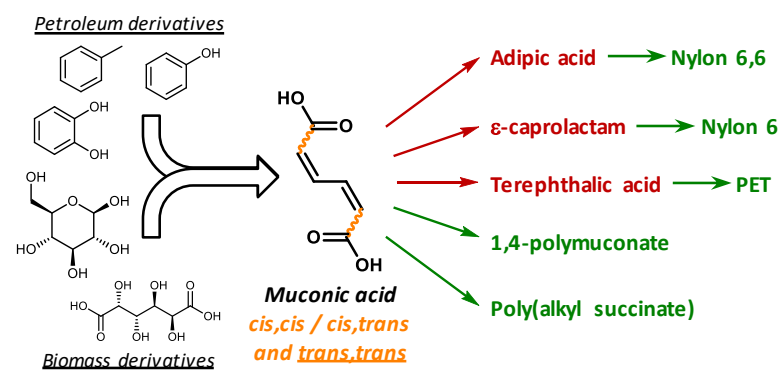

A complete review on the muconic acid synthesis (chemical and biotechnological), isomerization and valorisation into chemicals and polymers. 